\section{Saudade do partido: referencias nostálgicas entre militantes de las bases de sustentación de los gobiernos argentinos y brasileros (2003-2015)}

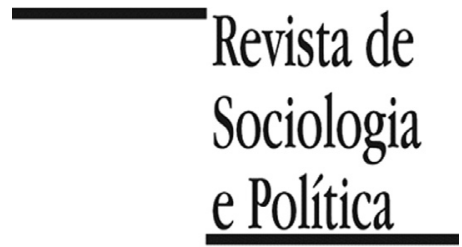

DOI $10.1590 / 1678-987317256202$

\author{
María Dolores Rocca Rivarola
}

\title{
Resumen
}

El artículo examina de modo comparativo la presencia de referencias nostálgicas entre militantes de organizaciones y espacios políticos que forman parte de las bases de sustentación de los gobiernos argentinos y brasileros desde 2003. Como parte de una investigación más amplia sobre la militancia oficialista, el fenómeno de nostalgia abordado en este trabajo es interpretado como una de las dos caras del impacto que escenarios político-electorales de intensa fluctuación en las identidades políticas y de volatilidad en el comportamiento electoral han tenido sobre las prácticas y concepciones de la militancia activa: por un lado, una adaptación a esas condiciones de la vida política - a través de la transformación del vínculo militante y de los formatos que asume esa militancia oficialista - y, por otro, un fenómeno paralelo - al que se dedica específicamente este artículo - de apelaciones nostálgicas referidas a un pasado de identidades políticas arraigadas y de partidos (o del propio partido) con una intensa vida orgánica y un fuerte lazo con el electorado. El trabajo adopta una perspectiva metodológica cualitativa, recuperando las interpretaciones de los propios actores a través del análisis de las entrevistas semi-estructuradas realizadas en cuatro distritos: las ciudades de San Pablo y Río de Janeiro, en Brasil; y la ciudad de Buenos Aires y algunos distritos del conurbano bonaerense - con especial foco en La Matanza - en Argentina (56 entrevistas desde 2013, y la consulta selectiva de otras 74 realizadas entre 2005 y 2010 para una investigación previa). A partir del agrupamiento de distintas categorías creadas en el proceso de codificación de las entrevistas se han identificado dos dimensiones de esa nostalgia: las apelaciones al perfil del militante del pasado, por un lado, y la referencia al contexto o condiciones en las que se militaba, por otro. El análisis cualitativo permite confirmar el peso de las referencias nostálgicas en los testimonios. Cabe destacar, de todos modos, que la presencia de esa nostalgia no es homogénea en ambos casos nacionales, ni entre distintas organizaciones (predominando entre los militantes del PT en Brasil y al interior de las redes del PJ argentino y, diluyéndose, en cambio, en las nuevas organizaciones nacidas por fuera del PJ durante el período kirchnerista), ni tampoco entre distintas generaciones de militantes. Asimismo, aunque las dos dimensiones de nostalgia mencionadas aparecen con fuerza en los testimonios brasileros, es la segunda dimensión la que predomina entre los argentinos. El artículo procura contribuir al debate sobre la militancia y el vínculo político en la actualidad. Asimismo, postula - aun inscribiéndose en la literatura que plantea el debilitamiento de los vínculos estructurales y psicológicos entre los partidos y los ciudadanos - la pertinencia de estudiar la militancia política activa, la cual paradójicamente ha persistido en esos contextos de fluctuación.

PALABRAS CLAVE: Militancia; Lula; Dilma; PT; Kirchner.

Recebido em 30 de Novembro de 2015. Aceito em 20 de Março de 2016.

\section{Introducción ${ }^{1}$}

\footnotetext{
${ }^{1}$ Agradezco las sugerencias y comentarios de los dictaminadores anónimos de la Revista de Sociologia e Política. También quisiera destacar especialmente la orientación, documentos, contactos, sostén institucional, espacios de discusión de la investigación, y ayuda que me brindaron Lincoln Secco
}

$\mathrm{E}$ 1 presente artículo se propone abordar las referencias nostálgicas presentes en los testimonios de militantes oficialistas, es decir, miembros activos de organizaciones pertenecientes a las bases de sustentación de los gobiernos argentinos y brasileros entre 2003 y 2015. Sobre la base de un trabajo de campo desarrollado en ambos países, se analizará comparativamente el modo en que las narrativas militantes aparecían cargadas de apelaciones nostálgicas a un pasado de identidades políticas arraigadas, de partidos (o de su propio partido) que habían tenido una intensa vida orgánica y un sostenido y permanente vínculo con el electorado, y se esbozarán argumentos para 
(USP), Eduardo Bellandi (PT-SP), Bernardo Cotrim (PT-RJ), Cristina Buarque (UFRJ), Cláudio Couto (FGV-SP), César Kiraly (UFF), Felipe Borba (IESP-RJ) y Carlos Metidieri Menegozzo (Fundação Perseu Abramo-PT). comprender los contrastes entre ambos países, e incluso entre distintos actores colectivos en cada caso, en torno a ese fenómeno.

La investigación en la que este trabajo se enmarca se desenvuelve a partir de un interrogante: ¿Qué sucede con la militancia política en contextos de volatilidad en el comportamiento de los votantes y de identidades políticas no inscriptas necesariamente en la pertenencia partidaria? Para responder a esa pregunta, deberíamos antes reflexionar sobre las características de esa fluctuación o volatilidad política.

Partimos, para ello, de un diagnóstico de transformación del lazo político (Manin 1992), y de una escena de formatos de representación diferentes a la concebida tradicionalmente como "democracia de partidos", la cual definía a los partidos a partir de su capacidad de configurar identidades políticas fieles al sello partidario, o de condicionar eficazmente la autonomía de los miembros, sometidos a la disciplina impuesta por la estructura partidaria. Si definimos a la identificación partidaria en directa relación con la vigencia de un voto constante (y unificado entre los distintos niveles) al partido de preferencia a lo largo de sucesivos procesos electorales, la escasa manifestación de fenómenos como la defección partidaria, y la nutrida participación en actos políticos de esa fuerza (Greene 2004), puede advertirse que esos supuestos indicadores son los que precisamente han sido sacudidos por las mutaciones en el formato representativo.

La caracterización de esos escenarios político-electorales transformados ha sido desarrollada por distintos trabajos. A nivel general o global, desde fines de los años ochenta y principios de los noventa, diferentes estudios abordaron lo que consideraban un fenómeno de crisis en el vínculo de representación de los partidos políticos con la ciudadanía (Wattenberg 1987; Craig 1988; Lawson \& Merkl 1988). Sin embargo, la lectura de crisis o declinación de los partidos ha sido discutida desde una perspectiva que plantea mutaciones, más que la progresiva desaparición o sustitución de los partidos por otras organizaciones (Manin 1992). Otros trabajos han analizado, en una línea similar, la proliferación de electores que, en las encuestas de opinión se niegan a identificarse con algún partido en particular, la caída en los niveles de afiliación a los partidos, el debilitamiento de los vínculos estructurales y psicológicos entre los partidos y los ciudadanos, y la posibilidad de los líderes políticos de prescindir de los cauces partidistas tradicionales, por lo menos, a la hora de establecer de un vínculo identitario con sus votantes (Montero \& Gunther 2002).

En los casos de Argentina y Brasil, la escena político-electoral inaugurada con la asunción de los presidentes Lula y Kirchner aparecía definida, más que por partidos de masas fuertes y comportamientos electorales e identidades políticas estables, por una marcada volatilidad electoral, la fluctuación política de los propios dirigentes (defecciones partidarias, reconstitución frecuente de los bloques parlamentarios por el ingreso y salida de legisladores de sus respectivos espacios políticos) y la personalización de la oferta electoral y en las estrategias de campaña.

Para comprender esas transformaciones en las identidades políticas en el contexto argentino han sido de especial utilidad las perspectivas de Cheresky (2006; 2007), Palermo y Novaro (1996), Pousadela (2007) y Svampa (2009). Aunque el peronismo se ha definido a sí mismo históricamente a través de un formato organizativo más movimientista que partidario (Levitsky 2003; Perón 2006), desde su surgimiento se caracterizó por la posibilidad de configurar identidades políticas duraderas y de mantener un electorado propio y estable a lo largo de los años. Todo ello, sin embargo, ha ido experimentando profundos cambios, iniciados en forma incipiente a partir del retorno a la democracia en 1983 (Vommaro 2006) e intensificados con la crisis de 2001 (Pousadela y 
Cheresky 2004). El PJ llegaría así a 2003 habiendo atravesado significativas modificaciones. Para los gobiernos de menemistas, Gutiérrez (2001) y Levitsky (2003) han señalado algunos cambios experimentados por el PJ en términos de su base electoral, el perfil de su composición interna (y el balance de fuerzas entre los sindicatos y las agrupaciones territoriales financiadas por los gobiernos municipales que el partido retuvo desde 1983), y sus dinámicas, mientras que Palermo y Novaro (1996) advirtieron las oscilaciones del presidente Menem en su relación con el partido. Levitsky (2003), asimismo, señala que la segmentación y descentralización de la estructura partidaria (con mucho margen de autonomía para las agrupaciones territoriales) habría sido clave durante el menemismo para evitar movimientos centrífugos de aquellos grupos y militantes a los que les disgustaba la línea nacional del partido favorable a las medidas económicas del gobierno. Sin embargo, es después de la década menemista, y de modo acentuado, con la crisis de 2001 y, luego, con la llegada de Kirchner al poder en 2003, que asistimos a una atomización de las redes partidarias (Leiras 2007). En palabras de Leiras, después de 1999, "con Menem fuera de la presidencia y Duhalde derrotado [por De la Rua en elecciones de ese $a \tilde{n} o$ ], el peronismo se convertía en un archipiélago de organizaciones de distinto tamaño y capacidad de movilización" (Leiras 2007, p.156). Ello se combinó con otros procesos como la proliferación de organizaciones de desocupados ("piqueteras") que competirían de modo directo en el territorio con el PJ (Svampa y Pereyra 2003), una desperonización de las apelaciones presidenciales durante el período 2003/2007 (Altamirano apud Natanson 2004; Rocca Rivarola 2015a) y una intervención partidaria (por orden judicial) y estado de acefalía que se prolongaría desde 2005 a 2008

Para el caso brasilero, aunque distintos autores han asociado esa misma fisonomía de la representación presente en 2003 no a transformaciones recientes, como en Argentina, sino a una configuración histórica más antigua (Mainwaring 1999; Pousadela 2007), se ha observado desde la transición democrática (1985) una progresiva profundización de esas tendencias. Así, no se producía una estabilización del comportamiento electoral (Kinzo 2005), y disminuía el número de electores que exhibían preferencias o sentimientos partidarios (Carreirão 2008), desarrollándose vínculos menos ideológicos y programáticos entre los partidos y el electorado (Mainwaring \& Torcal 2005). La escena partidaria se caracterizaba más bien por su contingencia, con grandes y rápidas variaciones (Palermo 2000). Manifestaciones de esos fenómenos han sido las campañas electorales centradas en los candidatos individuales y no en las fuerzas políticas (característica potenciada por el propio sistema electoral), altos niveles de volatilidad electoral, migraciones partidarias al interior de las bancadas parlamentarias, cierto desconocimiento en el electorado respecto de a qué partido pertenecen los principales líderes políticos, e incluso sobre cuáles son los partidos brasileros (Kinzo 2005). Mientras que algunos autores han anunciado una institucionalización y consolidación del sistema de partidos (Santos \& Vilarouca 2008), otros trabajos han señalado, en cambio, una intensificación de aquellas tendencias (Hochstetler \& Friedman, 2008), especialmente desde la llegada de Lula al poder (Paiva, Braga \& Pimentel 2007), advirtiendo una creciente desafección con los partidos en general. Incluso el propio PT, sindicado en distintos trabajos (Mainwaring 1999; Freire de Lacerda 2002; Kinzo 2005; Carreirão 2008) como una suerte de excepción, como un partido que lograba una efectiva identificación del electorado en términos de un voto por el propio sello partidario [legenda], sufrió desde los años noventa transformaciones sustantivas (Freire de Lacerda 2002; Guidry 2003; Power 2008; Amaral 2010a; 2010b; Secco 2011) que acortarían esa distancia respecto del funcionamiento de los demás partidos brasileros. 
${ }^{2}$ Cabría aclarar aquí que, tratándose de una investigación cualitativa, los argumentos formulados acerca de la militancia no tienen una pretensión de alcance más allá de los casos nacionales en cuestión, y de las localidades donde fue realizado el trabajo de campo (San Pablo, Río de Janeiro, Ciudad de Buenos Aires y algunos distritos del conurbano de la provincia de Buenos Aires).

\footnotetext{
${ }^{3}$ Defino la noción de oficialismo como el conglomerado de sectores organizados que van confluyendo, alineándose y
}

De todos modos, a diferencia de la mayoría de los demás partidos brasileros, el PT ha mantenido una vida interna en términos organizativos, y sostenidas redes de activismo orgánico a nivel nacional - aunque pudiese constatarse una declinación del "vínculo militante" (Rocha 2009) o de la misma militancia (Secco 2011). También ha exhibido un funcionamiento de sus autoridades (y procesos de selección de las mismas), pronunciamientos públicos como unidad política, disciplina interna, una continuidad de su sello en todo el territorio nacional brasilero para los procesos electorales y para el funcionamiento de su bloque parlamentario (Rocca Rivarola 2012). De ese modo, se produce la paradoja de militantes actuando en el seno partidario y siguiendo lógicas propias del mismo pero a la vez en un ambiente de volatilidad electoral e identidades políticas fluctuantes. Y en Argentina, aunque desde formatos diferentes al partidario, como veremos, la militancia político-electoral parece haberse multiplicado en los últimos años, especialmente a partir de 2010, con la muerte de Néstor Kirchner.

En otros términos, aunque la volatilidad electoral y la fluctuación política sean fenómenos característicos de los formatos de representación de Argentina y Brasil desde los gobiernos de Lula y Kirchner (2003), ello no ha resultado en la desaparición o redundancia de la militancia. Es precisamente esa persistencia de la militancia, dato devenido significativo en virtud del contexto que ha sido descripto, la que vuelve relevante un estudio de la misma. Si bien no ha desaparecido, sí, en cambio, podríamos pensar que aquellas transformaciones y fluctuación han impactado de algún modo sobre las condiciones en las que se desenvuelve la militancia, y sobre las visiones que militantes y dirigentes políticos y sociales oficialistas tienen acerca de la misma.

En trabajos anteriores (Rocca Rivarola 2013) he argumentado ya que el impacto de los contextos y condiciones mencionadas sobre la militancia oficialista consiste, por lo menos, en un doble fenómeno, de adaptación y nostalgia. ${ }^{2}$

En primer lugar, los actores han experimentado una adaptación a esas condiciones de fluctuación o volatilidad de la vida política en sus propias prácticas políticas cotidianas. Aunque aquella adaptación no será analizada en el presente artículo - y ha sido interpretada en otro trabajo propio (Rocca Rivarola 2015b) - cabe una mención respecto de la misma. Dos de sus dimensiones constituyen ejes de comparación entre ambos casos nacionales. Una primera dimensión de aquella adaptación es la transformación del vínculo militante, la cual presenta características similares en ambos casos nacionales. Esos vínculos aparecen como más diversos, flexibilizados, informales, individualizados y, crecientemente dependientes de una inserción laboral (temporal) en el Estado, o del nexo con un candidato particular o legislador, más que de una mediación colectiva u orgánica (de un partido, por ejemplo). Los modos de pertenencia se perfilan como más parciales, múltiples y superpuestos, siendo posible hablar ya no sólo de un electorado fluctuante, sino también de bases organizativas fluctuantes. Una segunda dimensión de la adaptación, y un punto de contraste entre ambos casos nacionales, se perfila al analizar las formas que asume la militancia oficialista. En Argentina, durante los gobiernos kirchneristas (2003-2015), se generalizó un modo de militancia política oficialista que no se plasmaba exclusiva y estrictamente bajo la forma de partidos políticos, sino de espacios reticentes a organizarse en términos partidarios y que tampoco llamaban a sus miembros a afiliarse a algún partido ya existente. La participación activa y pertenencia a estos espacios aglutinados dentro del oficialismo ${ }^{3}$ no ha implicado, entonces, la construcción de un partido propio ni la incorporación a otro. Sin embargo, no se trataba de un conglomerado de organizaciones kirchneristas, por un lado, y un Partido Justicialista (PJ), por otro, como compartimentos estancos, sino de superposiciones e interacciones muy particulares. En el caso brasilero, en cambio, el Partido dos Trabalhadores 
realineándose en torno a la figura presidencial. La noción no refiere a una coalición partidaria sino a un conjunto de organizaciones, movimientos, espacios políticos; a una base activa de sustentación del presidente, con actores sumamente heterogéneos y no necesariamente aglutinados por una identidad común (Rocca Rivarola 2013).

${ }^{4}$ Se ha usado en estas palabras el tiempo presente para el caso brasilero dado que al momento de escritura, la presidenta Dilma Rousseff ha sido suspendida de su cargo al iniciarse un polémico proceso de impeachment, pero no ha sido (aún) destituida. En Argentina, en cambio, desde diciembre de 2015, el kirchnerismo ya no conduce el gobierno, luego de la derrota electoral de su candidato, Daniel Scioli.
(PT) no ha sido un actor más dentro del conjunto oficialista aglutinado alrededor de la presidenta Rousseff (y antes, en torno a Lula), sino un núcleo organizado y organizador, que, aunque coexiste con otros sellos partidarios y organizaciones sociales afines al gobierno, constituye el espacio de confluencia del grueso de la militancia activa oficialista, y la presencia de militantes del PT al interior de las organizaciones no partidarias del oficialismo es notable. Allí, las transformaciones en las formas de la militancia son, entonces, las transformaciones acontecidas en el propio PT y no fuera de él. ${ }^{4}$

En segundo lugar, paralelamente a la adaptación ya mencionada a las condiciones fluctuantes de la vida política en sus propias prácticas políticas cotidianas, los militantes exhibían, en sus testimonios, definiciones nostálgicas y apelaciones a un pasado que caracterizaban como de identidades políticas arraigadas y de partidos (o de su propio partido, en el caso de los petistas) que habrían tenido una intensa vida orgánica y con un sostenido y permanente vínculo con el electorado. Esta referencia nostálgica constituye el núcleo de análisis del presente trabajo.

En términos de Boym (2001), la nostalgia - cuyo origen etimológico combina la noción de deseo, pesar o dolores (en griego, algia) con la de volver a casa (nostos) - es la añoranza por un hogar que ya no existe o que nunca existió. Un sentimiento de pérdida o dislocación, pero también un romance con la fantasía propia, una superposición de dos imágenes, la del hogar y el exterior, la del pasado y el presente, la del sueño y la vida cotidiana (Boym 2001, p.10).

Por supuesto, como veremos, la nostalgia como aflicción o sentimiento no significa, por sí sola, que aquel momento o espacio al que ésta refiere haya sido idéntico a cómo aparece en ella representado. En otros términos, el que los actores evoquen un pasado de determinadas características no garantiza que ese otro tiempo efectivamente las haya tenido. Sin embargo, dadas las discusiones académicas antes relevadas en torno a lo ocurrido con las identidades políticas y el comportamiento electoral y partidario en ambos países, la presencia de nostalgia o saudade en los testimonios de militantes oficialistas puede ser interpretada en tanto fenómeno derivado de esas transformaciones, y no como una mera propensión generacional.

Ahora bien, ¿qué características exhibía esa nostalgia en ambos países? ¿Qué regularidad presentaba según el perfil generacional de los militantes, su proceso de incorporación a las organizaciones de pertenencia y la trayectoria de esas organizaciones?

Se argumentará aquí que, en el caso argentino, la referencia nostálgica apuntaba a un pasado de identidades partidarias consolidadas, aun en un contexto de normalidad institucional intermitente (debido a los golpes de Estado que caracterizaron el escenario político argentino durante gran parte del siglo XX). Un pasado en el que el Partido Justicialista, aun revistiendo históricamente el peronismo un formato organizativo movimientista (más que partidario en los términos clásicos), habría ostentado la capacidad para configurar una identidad política duradera y para mantener un electorado propio y estable a lo largo de los años. Esa capacidad, sin embargo, iría experimentado profundos cambios, iniciados en forma incipiente a partir del retorno a la democracia e intensificados con la crisis de 2001 (Pousadela \& Cheresky 2004). En el caso de Brasil, aunque, como vimos, los períodos previos a la transición democrática no pueden ser descriptos del mismo modo que en Argentina, el pasado al que las referencias nostálgicas de militantes y dirigentes aluden es el pasado del propio PT. La nostalgia refería, en estos testimonios, a un período de intensa militancia barrial, sindical, intelectual y hasta parroquial (con las Comunidades Eclesiásticas de Base o CEB, de las que aún provenían algunos de sus activistas), en el marco de un partido heterogéneo de tendencias internas, de 
${ }^{5}$ En Argentina, el término "organizaciones sociales" adquirió un uso generalizado en la academia para referirse a organizaciones provenientes del espacio piquetero, en especial a aquellas que luego se incorporaron al oficialismo kirchnerista.

\footnotetext{
${ }^{6}$ Otras organizaciones militantes dentro del kirchnerismo hasta 2015, con las cuales no se hicieron entrevistas, fueron: Corriente Peronista Descamisados, Corriente Nacional Martín Fierro, Tupac Amaru, Octubres, Socialistas Para la Victoria, FORJA, etcétera.

${ }^{7}$ El lanzamiento por parte de CFK, en un acto el 27/04/12, de Unidos y Organizados (UyO) parecía inaugurar un espacio de aglutinamiento de aquellas organizaciones que no eran parte del PJ y que se encontraban más bien dispersos entre sí en su apoyo al gobierno kirchnerista. Intermitentemente, UyO funcionó como instancia de coordinación interna y articulación cotidiana en 2012 y 2013, pero no se constituyó como una fuerza orgánica ni permanente.
}

organización en núcleos de base, y que había apuntado a generar en el electorado un lazo identitario que el resto de las fuerzas políticas no estaba generando con la transición democrática.

Es decir, en ambos casos nacionales, existía, en la visión de los actores, un pasado en el que la militancia parecía desarrollarse en otras condiciones, y el propio perfil de los militantes era diferente. Esa nostalgia no se observaba, de todos modos, en la totalidad del oficialismo o base política del gobierno, advirtiéndose contrastes entre organizaciones. Por ejemplo, entre las redes locales del PJ y las nuevas organizaciones surgidas al calor del propio proceso kirchnerista, en Argentina, o también entre generaciones de entrevistados, en ambos países. Este artículo, que constituye un avance parcial de una investigación en curso, se interrogará, a partir de los testimonios de entrevistados de ambos países, acerca de algunas dimensiones de esa nostalgia o saudade.

El mapa de organizaciones de pertenencia de los militantes entrevistados abarcó, en el caso argentino, a) al Partido Justicialista - especialmente en el municipio de La Matanza, pero también en la ciudad de Buenos Aires, y en otros municipios del conurbano bonaerense como San Isidro, Avellaneda, Quilmes, etc.); b) sellos partidarios menores - Frente Grande, Partido Comunista Congreso Extraordinario (PCCE), e incluso dirigentes transversales del Frente para la Victoria sin partido de pertenencia - c) cuatro organizaciones que fueron identificadas durante el mandato de Néstor Kirchner como "organizaciones sociales" 2009), Movimiento Evita, Federación “Tierra, Vivienda y Hábitat” (FTV), Frente Transversal Nacional y Popular; d) centrales sindicales oficialistas, por lo menos durante una parte del período abordado - Confederación General del Trabajo (CGT) y fragmento oficialista de la Central de Trabajadores de la Argentina (CTA); y e) una serie de organizaciones militantes con distintos formatos y denominación - corrientes, movimientos, agrupaciones, espacios, etc. - que fueron surgiendo por fuera del PJ y reposicionándose al interior del kirchnerismo desde 2008, como La Cámpora; Nuevo Encuentro; Peronismo 26 de julio; Peronismo Militante; Carta Abierta; Kolina; Corriente Nacional de la Militancia; Movimiento de Unidad Popular (MUP). ${ }^{6}$ El arco de organizaciones fue más amplio en Argentina dada la proliferación de esos numerosos espacios al margen del Partido Justicialista, y no organizados como partidos, que fueron logrando una inserción en el Estado y que desarrollaron una movilización a favor del gobierno en el marco del espacio "Unidos y Organizados"7. Por otro lado, cabría una precisión sobre la inclusión de las redes del PJ en el oficialismo. Si pensamos en el modo de definir la pertenencia al oficialismo, es cierto que se advierten distintas intensidades entre las redes locales del PJ, por un lado, y algunas de las organizaciones kirchneristas más activas durante el segundo gobierno de Cristina Fernández de Kirchner (La Cámpora, Movimiento Evita, Nuevo Encuentro, etc.), por otro. E incluso, los símbolos movilizados por los entrevistados del PJ y sus organizaciones de pertenencia no siempre eran los mismos que los de otros actores colectivos del oficialismo, o incluso que los enfatizados por el propio presidente y presidenta. Pero, sin duda, esos entrevistados se consideraban a sí mismos entre 2003 y 2015 como parte del oficialismo, identificaban a Néstor Kirchner y Cristina Fernández de Kirchner como sus líderes, e incluso militaban activamente a favor del gobierno, todo lo cual justifica su inclusión dentro de la militancia kirchnerista.

Aunque en Brasil también existen numerosas organizaciones no partidarias que han exhibido un expreso y activo apoyo a los gobiernos liderados por el PT, la presencia de militantes petistas en esas organizaciones era notable (es decir, en un fenómeno frecuente de múltiple pertenencia de los militantes al interior del universo oficialista). Por ello, las entrevistas en Brasil han sido mucho más a partidos de la base del gobierno, y han incluido a menos organizaciones no 
${ }^{8}$ La relación de este partido con los gobierno de Lula y Dilma fue ambigua y oscilante, y con una heterogeneidad entre las posiciones en cada Estado brasilero. Sin embargo, al momento del trabajo de campo aún era considerado por los propios actores como dentro de la base parlamentaria del gobierno. En 2016, las tensiones y distanciamiento de algunos dirigentes del PMDB respecto del gobierno finalmente implicaron un rompimiento orgánico.

${ }^{9}$ La decisión de incluir al MST en el oficialismo se ha basado en la relación histórica del MST con el PT, su vinculación con el Estado durante estas administraciones y su posicionamiento en apoyo al gobierno en momentos clave en los cuales la dirección del movimiento interpretó que estaba en juego la continuidad de aquel. Para una argumentación detallada sobre esta decisión metodológica, ver Rocca Rivarola (2013).

\section{Dimensiones de la nostalgia al interior de la militancia oficialista}

${ }^{10}$ Sobre la construcción pública de la memoria en interacción con la narrativa individual, ver Franco (2007). partidarias. Específicamente, en Brasil, el mapa de organizaciones relevadas incluyó centralmente al Partido de los Trabajadores (PT), y, dado que se trata de un partido de tendencias internas, se procuró el acceso a varias de ellas, como Construyendo un Nuevo Brasil (CNB), Democracia Socialista (DS), el campo más amplio Mensaje al Partido, El Trabajo, Izquierda Marxista, PT de Luchas y Masas (PTLM), PT Nuevo Rumbo, Articulación de Izquierda, así como a entrevistados no pertenecientes orgánicamente a ninguna tendencia. También comprendió al Partido Comunista de Brasil (PCdoB); el Partido Democrático Laborista (PDT); Partido del Movimiento Democrático Brasilero (PMDB) ${ }^{8}$. Y, por fuera del espacio partidario, a organizaciones como la Marcha Mundial de Mujeres (MMM), la Central Única de Trabajadores (CUT), Consulta Popular y el Movimiento de Trabajadores Rurales Sin Tierra (MST) ${ }^{9}$.

En Argentina, el trabajo de campo aún está en curso (hasta el momento, 13 entrevistas) y, para el caso brasilero, el análisis cualitativo de todo el material producido (43 entrevistas) no ha concluido. Por ello, este artículo constituye una aproximación preliminar. Asimismo, se han analizado selectivamente algunas de las entrevistas realizadas a militantes y dirigentes locales de distintas organizaciones oficialistas para una investigación anterior - en los mismos distritos - también referida al oficialismo desde 2003 pero con otros interrogantes (32 en Brasil y 42 en Argentina).

El análisis de las narrativas militantes sobre el pasado se desarrollará tomando a los procesos de interpretación que los entrevistados hacían de sus propias experiencias como mediados por creencias, actitudes y valores, constituyendo sus testimonios no una mera descripción de eventos, sino una valoración y evaluación de los mismos (Sautu 1999; Navarro 2007), y una selección de la práctica política pasada desde el presente o, en términos de González, como "pasado revisitado" (González 2015). Es por ello sugerente la exhortación de James (2004):

\footnotetext{
"Debemos tener una vez más la precaución de no caer en los supuestos de un realismo ingenuo ni imaginar una cualidad mimética en las narraciones orales, cuando expresan conciencia y sentimientos. [...] Si bien el testimonio oral es, en efecto, una ventana hacia los aspectos subjetivos de la historia - el universo cultural, social e ideológico de los actores históricos - es necesario decir que la visión que proporciona no es el mero reflejo transparente de los pensamientos y sentimientos tal como realmente fueron o son. Como mínimo, la imagen está refractada y el cristal de la ventana es poco claro" (James 2004, p. 128).
}

Pero, aun desde esos reparos, se seguirá aquí la apelación de este mismo autor a "tratar la calidad subjetiva y textual del testimonio oral como una oportunidad única y no como el obstáculo a la objetividad histórica y el rigor empírico" (James 2004, p.127). Se asumirá una perspectiva que "implica lógicamente la conclusión de que es preciso tomar seriamente las afirmaciones de los actores sobre sus propias acciones" (Balbi 2007, p.37). También se tendrá presente el hecho de que los entrevistados, al ser militantes, actuaban en el marco de espacios orgánicos (partidos, corrientes, movimientos, agrupaciones, etc.) en los cuales también se producía un procesamiento colectivo - y hasta público - del pasado y del presente, forjándose narrativas "oficiales" que coexistían y se retroalimentaban con las concepciones y memorias que esos actores pudieran construir individualmente. ${ }^{10}$

No es el propósito de este trabajo analizar las transformaciones que efectivamente se produjeron en el PT y el peronismo desde la redemocratización, algo que incluso ya ha sido abordado por Gutiérrez (2001), Levitsky (2003), Palermo y Novaro (1996), entre otros, para el caso argentino, y por numerosos 
${ }^{11}$ En un trabajo anterior propio fueron examinadas, a su vez, algunas

transformaciones sufridas por ambos partidos desde la asunción de Kirchner y Lula (Rocca Rivarola 2012).

${ }_{12}$ Para estudios sobre la mutación en la composición del electorado del PT, ver Veiga (2007), Samuels (2008) y Singer (2012).
${ }^{13}$ Conducida por Alicia Kirchner, hermana del ex presidente y ministra de Desarrollo Social, KOLINA se desarrolló desde el interior de ese ministerio. Kolina se autodefinía con una noción que habilitaría múltiples pertenencias: "quienes participan [en Kolina] no pierden su identidad ni la de su agrupación, ni la de su movimiento o partido, pues se amalgaman en una corriente autores en el caso brasilero (algunos ya mencionados antes) ${ }^{11}$, como Amaral (2010a; 2010b), Samuels (2008) y Secco (2011) ${ }^{12}$. El objetivo es, en cambio, reflexionar, a partir de las entrevistas realizadas, sobre las referencias nostálgicas advertidas en los testimonios de militantes y dirigentes locales oficialistas - muchas de las cuales aluden a ese pasado organizativo.

Para ello, se han agrupado distintas categorías utilizadas en el análisis cualitativo de las entrevistas ("códigos"), organizándolas en torno a dos dimensiones o ejes más amplios. Por un lado, el perfil del militante del pasado contrastado por los propios actores con el actual: su nivel de compromiso, predisposición o intensidad, los procesos de burocratización o profesionalización que lo habrían transformado, y la cuestión de la formación política o doctrinaria. Por otro lado, las condiciones en las que se milita, con una apelación a un pasado en el que ese ambiente donde se desarrollaba la militancia es valorizado: el modo en que se hacía campaña electoral, la cuestión de los recursos estatales y su incidencia en la militancia, el deterioro de los espacios de militancia, el rol de los partidos y de las identidades partidarias, el vínculo con los afiliados y votantes, y el peso de los militantes frente a las figuras populares o con mandatos legislativos.

Las apelaciones nostálgicas no aparecían de modo homogéneo en ambos casos nacionales y en el grueso de las organizaciones, movimientos y espacios oficialistas observados. Aunque ambas dimensiones de la nostalgia (en torno al perfil del militante y, por otro lado, a las condiciones en las que se militaba) se advertían en los testimonios en Brasil, en Argentina la primera dimensión estaba menos presente.

En las entrevistas brasileras predominaba, entre los militantes del PT de distintas tendencias o corrientes internas, la nostalgia respecto del pasado militante del propio partido, con un contraste esperable entre los entrevistados menores y mayores de 35/40 años; y también entre quienes se sumaron al partido con posterioridad al triunfo de Lula en 2002 y quienes exhibían, en cambio, una trayectoria previa en el PT. Entre los militantes de otras fuerzas (PCdoB, PDT), aunque existían referencias nostálgicas, éstas se observaban más bien alrededor del contexto en el que se militaba (segundo eje que analiza este artículo) que sobre las características del propio partido.

En Argentina, por otro lado, el fenómeno de nostalgia tenía una presencia menor entre los militantes de organizaciones surgidas o fundadas durante el propio período kirchnerista. Estaba virtualmente ausente entre los miembros más jóvenes de esos espacios, sí advirtiéndose, en cambio, entre algunos militantes mayores de 40 años al momento de las entrevistas, que habían pasado, antes de integrarse a estas organizaciones, por el PJ o por otros espacios políticos. Pero, de modo general, entre los militantes que integraban la galaxia de organizaciones kirchneristas nacidas luego de 2003 (y varias de ellas, luego de 2008 - momento del conflicto por la resolución 125 de retenciones móviles a la soja - y de 2010 - muerte de Néstor Kirchner) - Kolina ${ }^{13}$, Frente Transversal Nacional y Popular $^{14}$, Corriente Nacional de la Militancia ${ }^{15}$, La Cámpora, Nuevo Encuentro ${ }^{16}$, etc. - la ponderación elogiosa del presente en términos políticos y militantes - la idea de una reactivación de la militancia, por ejemplo - no dejaba demasiado lugar para una reivindicación del pasado, como refleja este testimonio de Ruth (34 años):

"En los noventa, la palabra militancia, si la conocía, era sólo de oído. En mi ciudad eran todos radicales. No había una apertura, si no eras hijo de alguien que había estado, difícilmente te pudieras incorporar a la política, a los comités. [...] Yo soy parte de la juventud que descubre la política con Néstor, con Cristina [...] En otra etapa, muchos de los jóvenes que están involucrados, como en mi caso, jamás hubiésemos estado en un lugar de gobierno. No hubiese habido 
militante" (Kolina Capital 2017).

${ }^{14}$ El Frente Transversal

Nacional y Popular nació durante el gobierno de Néstor Kirchner, a partir de una relación personal de décadas entre el propio presidente y Edgardo Depetri, dirigente sindical de Santa Cruz y luego diputado nacional. Contaba, durante los gobiernos kirchneristas una marcada composición sindical pero también con una construcción territorial propia, gracias a la gestión de planes sociales como el Plan Argentina Trabaja.

${ }^{15}$ La Corriente Nacional de la Militancia (CNM) se fundó en 2010, autodefiniéndose como "un espacio de encuentro de distintos referentes y dirigentes que acompañamos este proceso político" (LTIO Universidad 2014). Con poco desarrollo territorial propio, la CNM se mantuvo como espacio de dirigentes, legisladores y funcionarios.

${ }^{16}$ Nuevo Encuentro surgió en 2009, como la refundación nacional de un anterior partido vecinal, "Nuevo Morón", nacido en 2002 desde el Estado municipal de ese distrito durante la gestión de Martín Sabbatella. Poco después de su fundación como sello para la candidatura de Sabbatella a diputado nacional - Nuevo Encuentro se integró al kirchnerismo.

\footnotetext{
${ }^{17}$ Las redes locales del PJ se organizan en "agrupaciones", las cuales representan a facciones al interior del partido, o bien a pequeños grupos. A su vez, una agrupación puede abrir/crear "unidades básicas" (UBs). El
}

posibilidad de que la hija de una empleada de correo y un metalúrgico llegase a ser diputada, con el esfuerzo y con [un título en] Ciencias Políticas, qué vas a hacer de la vida. ¿No te preguntaba la gente qué era eso? La palabra 'política' ni sabían bien qué era, la asociaban a gobierno". (Ruth, militante de La Cámpora, legisladora en la provincia de Buenos Aires, 9 nov. 2015).

E, incluso en algunos militantes de edad más avanzada en esas organizaciones, ese presente ponderado, cuando era contrastado con la militancia del pasado, no lo era en términos nostálgicos, sino al contrario, en una valoración de la militancia actual. El ejemplo de Genaro (48 años), quien se había iniciado políticamente en el PJ, se había retirado del partido en los años noventa, y recientemente había comenzado a militar en La Cámpora, ilustra esos casos. Para él, un contraste con "los pibes de ahora" era que no habían sufrido tantas "decepciones" políticas como él, que enumeraba como ejemplos las políticas neoliberales del menemismo, el fallido camino recorrido por el Frente Grande al final de esa década, etc. (Genaro, militante de La Cámpora y funcionario del gobierno nacional en la ciudad de Buenos Aires, 6 mayo 2014). La Cámpora es en ese sentido una organización paradigmática de la visión sobre el presente que predominaba dentro la galaxia de nuevos movimientos, agrupaciones y espacios que fueron surgiendo en la última etapa de los gobiernos kirchneristas, y a la vez se trata de una organización muy particular dadas sus dimensiones, la gravitación al interior del kirchnerismo y su modo de surgimiento. Los testimonios en primera persona de miembros de la mesa nacional de La Cámpora recogidos por el libro periodístico de Russo (2014) sugieren la existencia de una estrategia de Néstor Kirchner, especialmente luego de su propio mandato, de promover el desarrollo de una "orgánica de la juventud" y que se convirtiera, en un futuro, en una suerte de fuerza propia de Cristina, más leal que el PJ y más organizada que el universo de organizaciones sociales, centrales sindicales, movimientos, y espacios que habían conformado el kirchnerismo desde 2003. Así, a partir de unas primeras reuniones pequeñas y algunos viajes al interior por parte de un núcleo inicial de dirigentes y funcionarios, La Cámpora se habría ido configurando hasta un momento de gran visibilidad en 2008, en pleno conflicto agropecuario. El momento exacto de nacimiento de la agrupación, sin embargo, oscila según el testimonio. Entre 2009 y 2015, La Cámpora exhibió un crecimiento exponencial en términos de dimensiones (aunque, al no constituir un partido, no ha presentado padrones de afiliados ante la justicia), capacidad de movilización, presencia territorial y una gran inserción en cargos estatales. En los entrevistados de la agrupación, el presente, entonces, era enunciado en una ponderación elogiosa, sin nostalgia respecto de la militancia del pasado.

Y, sobre todo, aquella nostalgia que los militantes del PT en Brasil portaban respecto de un pasado previo a la llegada al gobierno, y anterior incluso a la conquista de gobiernos municipales y estaduales durante la década del noventa - es decir, antes de su inserción institucional en el Estado y de las transformaciones organizativas que la corriente mayoritaria fue implementando sobre el partido durante la conducción de José Dirceu desde 1995 - difícilmente podría repicarse en las organizaciones argentinas mencionadas en torno al pasado de la propia organización, dado que la propia historia de éstas era relativamente nueva, y se inscribía ya en los gobiernos kirchneristas.

En el caso de los militantes de las redes locales del $\mathrm{PJ}^{17}$ de La Matanza Agrupación Ramón Carrillo (ARC), que ha gobernado el distrito durante varios años, y agrupaciones menores aliadas (como la "Agrupación Eva Perón AUD", "Agrupación Voluntad Peronista", "Agrupación Los Muchachos del Mercado Central", "La Matanza. Conducta Peronista - Juventud", "Agrupación Eva Duarte - Marisa Guerín", "Agrupación Caminante Peronista", "Agrupación Nacional Movimiento Peronista 11 de marzo de 1973”, etc.) - donde fueron 
estatuto del PJ en 1991 contemplaba a éstas como "el órgano primario del partido". Se trata de locales (sedes) a la calle situadas en los barrios.

18 Para un análisis de esas autodefiniciones por parte de los militantes de distintas agrupaciones del PJ de La Matanza que resaltaban la capacidad de movilización (de militantes, fiscales, etc.) y el funcionamiento aceitado del partido a nivel local en ese distrito, ver Rocca Rivarola (2012).

19 Por "renovación" hay aquí una alusión implícita a la disputa interna que vivió el peronismo luego de la derrota electoral de 1983, y donde la dirigencia "renovadora" impugnaba a los sectores que habían controlado el partido desde la muerte de Perón. Para análisis sobre el peronismo renovador, ver Aboy Carlés (2001), Levistky (2003) y Altamirano (2004)
${ }^{20}$ El Movimiento Evita se fundaba en un acto en el estadio Luna Park en mayo de 2005, como producto del aglutinamiento de distintos sectores y redes, algunos provenientes del PJ, otros de organizaciones territoriales menores (incluida una escisión del Movimiento Quebracho), y también del Movimiento de Trabajadores Desocupados Evita (MTD-Evita), nacido éste en 2002, antes de la presidencia de Néstor Kirchner.

21 Cabría hacer dos aclaraciones. En primer lugar, realizadas hasta el momento la mayoría de las entrevistas a militantes justicialistas, las apelaciones nostálgicas no eran generalmente formuladas en torno a su propia organización distrital, definida por ellos como eficaz, exhaustiva en su forma de hacer campaña, arraigada en el electorado, etc. ${ }^{18}$, sino en torno al contexto u escenario nacional en el que desarrollaban su militancia. En esa línea, y para la campaña de 2007, el dirigente máximo de La Matanza, Alberto Balestrini, sostenía ante la prensa local un argumento que sería reproducido en las entrevistas por otros militantes del oficialismo local, y que insinuaba una suerte de cruzada por la recuperación del PJ, desafío en el que La Matanza, en tanto histórico bastión electoral del peronismo, debía perfilarse como una suerte de vanguardia, de embrión desde el cual esa gesta podría ser llevada a cabo y extenderse a nivel provincial y nacional:

"En esta elección tendremos que redoblar esfuerzos porque debemos tener un triunfo no sólo en nuestro distrito, sino en toda la provincia, porque es la última reserva que le queda al peronismo en nuestro país [resaltado propio] [...] Hoy el partido no existe como tal, es una conjunción de partidos provinciales, en muchos casos conducidos de forma feudal. Tenemos que reinventar una segunda renovación ${ }^{19}$ del peronismo" (Balestrini 2007).

Pueden ser incluso interpretados dentro de esa nostalgia la insistencia de esos militantes y dirigentes matanceros en utilizar localmente la iconografía justicialista (fotos de Perón y Eva Perón en los actos políticos, el canto de la Marcha Peronista, la alusión resaltada al carácter peronista de los candidatos locales) en un momento en el que gobierno nacional parecía omitir deliberadamente la movilización de esos símbolos (campañas de 2005 y 2007) - algo de lo que esos entrevistados, además, se quejaban de modo explícito - y el llamado a que el peronismo volviera a ocupar el lugar que le correspondía dentro del oficialismo, todo lo cual configuraba una tensión latente, que ha sido analizada en un trabajo previo (Rocca Rivarola 2015a).

\section{a) El militante ayer y hoy}

Una primera dimensión que podríamos identificar del fenómeno de nostalgia se relacionaba con el perfil del militante, su nivel de compromiso y predisposición a distintas tareas, su carácter voluntario o bien profesionalizado, y su formación política y doctrinaria. En el contraste advertido en los testimonios entre el supuesto estado de la militancia en la actualidad y el modo en que se recordaba o se pensaba que la misma era hace aproximadamente tres décadas, se perfilaba la casi mítica figura del "militante de antes", éste era portador de un compromiso y de lealtades menos efímeras, menos dispersas, con una formación política vasta y dispuesto a hacer cualquier actividad - desde ocupar un cargo estatal decisivo y representar a su organización en reuniones clave con otros sectores, hasta pintar una pared o repartir volantes en algún ámbito de base. Así era planteado por Octavio, militante del Movimiento Evita ${ }^{20}$ (51 años ${ }^{21}$ ), y por Salvador, dirigente local del PJ en zona norte (31 años):

"Y el problema es que es muy difícil, porque vos en los [años] setenta tenías que estar de acuerdo con tres cosas: el peronismo, el socialismo y la lucha armada. Como te jugabas la vida, los niveles de compromiso eran enormes. Hoy en día no sabés muy bien con qué tenés que estar de acuerdo, y como los niveles de compromiso son laxos te enojás, es muy difícil. [...] Yo lo que creo es que una estructura organizativa como la de los setenta no funciona. Una estructura centralizada, con una mesa ejecutiva, referentes seccionales, no funciona. En primer lugar, porque los niveles de compromiso son distintos. Cuando empecé a militar me agarró la primera persona que a mí me condujo, venía el compañero y me decía "tenés que agarrar una brocha e ir a pintar toda la ciudad" [con mensajes politicos en las paredes y muros], y yo iba y lo hacía. Pero ahora no hay ni uno de esos. Y el compañero [se refiere a él mismo] está viejo ya (risas). Entonces, como no hay niveles de representación que permitan un "porque te lo digo yo" [...] Segundo porque los pibes de ahora tienen menos niveles de 
las edades citadas de los entrevistados son las que tenían al momento de la entrevista. En segundo lugar, los nombres utilizados para citar a los entrevistados son ficticios. Ello obedece a la decisión metodológica de preservar sus identidades.

${ }^{22}$ El MUP fue fundado en 1999 sobre la base de una organización de vertiente anarquista, AUCA (rebelde en lengua mapuche) oriunda de la ciudad de La Plata y con algo de presencia en la universidad y en territorio. Durante el gobierno de Kirchner, experimentaría, según Schuttenberg (2011) una reconfiguración identitaria paralela a su integración de al mismo. formación, te discuten más, te mandan al carajo. Entonces el nivel de debate antes de tomar una decisión es mucho mayor" (Octavio, militante del Movimiento Evita, 5 mar. 2008).

"En algún momento, la política tenía valoraciones. La Argentina tenía un alto nivel de movilización política y de participación, en las dictaduras. El advenimiento de la democracia hizo del valor de la lealtad una cosa muy rígida, se militaba sin esperar cargos partidarios porque no se los conocía. Mis padres, y seguramente hay otros mayores que les van a decir "yo en realidad fui diputado y ni sabía lo que era ser diputado, si yo no había conocido lo que significaba eso". Mi propio viejo fue jefe de columna de Montoneros. Fue un tipo importante de la resistencia, que estuvo preso en el '76 y no había sido jamás nada. Era militante. El cargo era ser jefe de militantes y que la gente reconociera a alguien como dirigente político. Mi viejo fue senador en el ' 87 y dice "yo cuando entré no sabía lo que era ser de una comisión [se refiere a una comisión parlamentaria], qué era una comisión". [...] Pasamos de una lealtad absolutamente inflexible, que era la lealtad significaba la muerte, a una lealtad moral o ética o partidaria, pónganle el título que quieran, a una lealtad financiada, en un momento en una estructura en la que, si no tenías recursos, no podías participar de la interna porque en realidad la lealtad - no es comprada porque no alcanza la palabra - estaba cercada por el poder. Hasta un escenario donde la lealtad es la condición, como es hoy. Hoy es exactamente al revés. Y que en muchos casos tiene que ver con la flexibilidad de la norma. O sea, a ver, cuál es el mérito de ser leal si uno no sabe en realidad cómo va a ser el proceso de selección de candidaturas dentro de seis meses" (Salvador, dirigente local del PJ en zona norte del conurbano, 18 feb. 2009).

Otros testimonios ilustran esa nostalgia en torno al nivel de compromiso y disposición del militante en el pasado. Paulino, militante del PJ de La Matanza, cercano a los 40 años de edad (entrevistado el 29 nov. 2007), por su parte, se refería al proceso de conformación de la lista de concejales [figura similar a la de los vereadores en Brasil] en 2007, relatando cómo había tenido que convencer a varios militantes de su propia localidad de salir a participar en la campaña electoral sin pedir un lugar en aquella lista electoral o cargos a cambio de ese compromiso. Camila, dirigente del Movimiento de Unidad Popular (MUP) $)^{22}$ de 36 años (13 nov. 2013), se lamentaba por los numerosos casos de "compañeros que a lo largo de estos años fueron acomodando su vida, consiguiendo trabajo, estando en mejores condiciones económicas, y, si bien votan al kirchnerismo, se han alejado de la militancia activa porque cambiaron sus condiciones materiales". Y Héctor, militante de Kolina de 46 años, recordaba su inicio en la militancia peronista, en el momento del retorno de la democracia formulando un contraste con fenómenos y perfiles que asociaba a la militancia actual:

"Jamás se me hubiera ocurrido cobrar por pintar una pared. Y los noventa creo que corrompieron a la militancia. Si bien yo no estaba participando, siempre tuve vínculos, y en las internas del PJ tenía un precio el voto. Si eras un puntero y tenías 50 afiliados, cada afiliado que llevabas a votar era una mercancía, y generó un tipo de militante político que después se volvió puntero, estaba mercantilizado. Y eso fueron cosas que quedaron, todavía vinculadas a la política. Uno estando al frente de una organización, te vinculás con lo que te decía yo, vamos a construir a los barrios, pero sin embargo hay gente que se acerca a militar con la lógica de "bueno, pero ¿qué hay?” [a cambio de militar]. ¡Hay una propuesta de construir! Pero tampoco culpo a la persona que por ahí fue formada de esa época, y entiende que la militancia pasa por militar para alguien si hay algún recurso. No termina siendo genuina esa construcción porque aparece otro en las antípodas de tu pensamiento y te ofrece un poco más y se lleva esa construcción, entonces es todo muy endeble. Antes estaba lo de los cautivos, porque mi familia es peronista soy peronista, sin mucha evaluación, ¿no es cierto? Una cosa más de identidad, era como automático, ahora lo que veo son militantes que están ahí al mejor postor" (Héctor, militante de Kolina en zona norte del conurbano bonaerense, 14 nov. 2013). 
En este testimonio se conjugan distintos diagnósticos y referencias nostálgicas. Por un lado, la imagen de un pasado de preferencias electorales más estables, ancladas en identidades políticas consolidadas, y más determinantes éstas incluso que una decisión programática o instrumental para la definición del voto. Por otro lado, se advierte una lectura sobre el punto de inflexión ocurrido en las condiciones en las que se desarrollaba la militancia: la década del noventa, durante la cual habría operado una suerte de mercantilización de la actividad política. Esa lectura estaba muy presente en militantes mayores que habían pasado en algún momento por el PJ y se habían alejado de éste y pertenecían ahora a otras organizaciones kirchneristas.

Sin embargo, era en la caracterización sobre el presente donde se hallaban algunos contrastes entre estos mismos militantes: mientras que para algunos, esa mercantilización formaba parte de la peyorativamente denominada "vieja política" (vista como iniciada en los noventa y como neutralizada por el kirchnerismo), para otros, había aún ciertos rasgos de continuidad respecto de la misma. Esta segunda lectura de continuidad aparecía transversalmente en distintos entrevistados que habían pasado por el PJ en su pasado, pero era la primera en cambio, la que predominaba entre militantes que se habían iniciado políticamente ya fuera del PJ. Estos contrastes, marcados en algunos casos por el tipo de organización de pertenencia más que por la edad del entrevistado, sugieren que, por lo menos, la nostalgia no aparecía meramente como un fenómeno de corte generacional al interior de la militancia kirchnerista.

En Brasil, los testimonios en esta misma orientación de una nostalgia respecto del perfil del militante eran más numerosos y recurrentes. Tan sólo a modo de ejemplo, Leonel (41 años) y Enrique (47 años), el primero, profesor universitario vinculado al PT y el segundo, militante histórico del partido, ambos miembros de un núcleo del PT - luego volveremos sobre lo sucedido con los núcleos - sostenían que el antiguo perfil de militante voluntario, con un compromiso político activo disociado de cualquier relación laboral, y una elevada formación política se había contraído significativamente en el PT.

"Leonel: Como militantes comunes del PT, nosotros hacíamos esas actividades electorales voluntarias. Boca de urna [hacer campaña en la puerta de los lugares de votación mientras la gente espera para votar, algo que los últimos años fue prohibido por la justicia electoral brasilera] para los candidatos mayoritarios, pero principalmente participábamos de la lucha interna. Discusiones internas, en las previas [elecciones internas], por ejemplo, tomar una posición. Hicimos un boletín para difundir nuestras ideas. Otros núcleos también tenían eso. La cuestión es que sólo el nuestro siguió haciéndolo. En los años noventa había varios núcleos que hacían eso. Nosotros continuamos. Ahí, y esto es una opinión personal, creo que no existe más militancia de ese tipo en el PT en los últimos diez años. Ya no es posible" [el resaltado es propio].

Enrique: Históricamente, las Secretarías de Formación existieron en el PT mucho antes de la creación de la Escuela de Formación, que es nacional. [...] Y particularmente, la Secretaría Estadual de Formación siempre tuvo una vida muy fuerte en el Estado de San Pablo. Y yo participé en dos colectivos de esas secretarías, municipal y estadual, en la segunda mitad de los noventa, y ya era muy nítida la diferencia de perfil entre el militante de la década del ochenta y la década del noventa. En la década del ochenta era un militante que de hecho venía de un movimiento social, de un sindicato, de las CEB [Comunidades eclesiales de base], del movimiento estudiantil. Entonces ya, antes de entrar al PT, tenía una formación de izquierda. A partir de los años noventa, el interés del afiliado, y eso lo percibís nítidamente cuando vas a hacer formación política para él, pasa a ser un interés meramente electoral. Entra en el PT con interés de candidatearse a concejal [vereador] o pensando en eso. Tanto es así que había cosas que funcionaban muy bien en la formación política para aquel militante con una trayectoria anterior de participación política y que ya no funcionan más [y relata aquí un ejercicio llamado "fábrica", en el que, a través de un juego de roles de 
${ }^{23}$ Una caracterización similar en términos de un supuesto déficit de formación de los militantes más jóvenes ha sido advertida, en Argentina, por González (2015) en sus entrevistas con algunos militantes de la Juventud Peronista de los años setenta de Bahía Blanca (en el sur de la provincia de Buenos Aires).

${ }^{24}$ La FTV surgió en los ochenta, como una cooperativa en el asentamiento El Tambo, en La Matanza, donde se habían producido tomas masivas de tierras. Su desarrollo territorial se basó en la organización colectiva para la provisión de servicios básicos, y, a partir de la expansión del desempleo, utilizó el corte de ruta como modo de reclamo (Delamata \& Armesto 2005). Su vínculo con Kirchner se remonta a las elecciones presidenciales de 2003 empresario y trabajador se les mostraba a los nuevos militantes la expropiación de plusvalía, y cómo dejó de ser usado en los cursos de formación]" (Entrevista con Leonel y Enrique, militantes sin corriente dentro del PT, San Pablo, 20 dec. $2013)^{23}$.

Esa nostalgia respecto de la formación política del militante del pasado (inicios de la redemocratización) también aparecía ilustrada en la caracterización que hacían Fabiano (48 años), militante petista de la tendencia Democracia Socialista (DS), y Wilhelmina (46 años), militante del aliado Partido Comunista do Brasil (PCdoB). Fabiano (entrevistado el 14/08/2013) recordaba el PT de los años ochenta como un ámbito muy rico en formación política de los militantes, que resultaba en un proceso de crecimiento personal, y señalaba, en cambio, para la actualidad, un debilitamiento de los cuadros, y la existencia de militantes con altos cargos partidarios que en el pasado no hubieran siquiera permanecido como militantes. Wilhelmina, por su parte, afirmaba:

\begin{abstract}
"Te voy a decir algo, pero quisiera que lo oigas con la noción de que es una opinión muy personal. No es la posición del partido. Creo que en esa época teníamos una disposición porque las reuniones se hacían así. Se hacía un análisis de la coyuntura internacional, después de la de América Latina, y se analizaba nacionalmente para después ver lo local. Eso obligaba al militante a estudiar, a estar informado de lo que estaba pasando en ese momento. No podía ir a la reunión con una opinión personal. Para entender las protestas en la calle, no bastaba con estar en la calle. Tenía que estar estudiando, leyendo, informándose. Y ahí se estaba en condiciones de hacer un análisis más ideológico. Y desde ese lugar ideológico, trazar perspectivas estratégicas para, en el momento, decidir prácticamente qué era lo necesario. Era una composición de pensamiento. Hoy ya no vivimos más eso. Vivimos reuniones muy atrasadas, de una urgencia que no te permite planificación, que no permite una visión general y analítica. Eso es un problema. Porque a veces las personas confrontan una posición con otra y ahí quien tiene un poco más de poder institucional conduce a una opinión sin haberse apoyado sobre el marco de las posiciones" (Wilhelmina, militante del PCdoB en Río de Janeiro, 19 ago. 2013).
\end{abstract}

Las cuestiones recién mencionadas, del militante del pasado, voluntario y formado, se vinculan con otra apelación nostálgica respecto del perfil del militante: la plasmada en el contraste del pasado con el diagnóstico presente de un militante profesionalizado (o burocratizado, en los propios términos de algunos entrevistados). Ese elemento emergía en algunas entrevistas argentinas, como con integrantes de la organización social Federación Tierra, Vivienda y Hábitat (FTV). Es el caso de Jesús, dirigente de la organización ${ }^{24}$ en el oeste del conurbano bonaerense y legislador (52 años), que criticaba a otras organizaciones sociales por "mimetizarse con el Estado" y consideraba que,

"Vos no podés basar tu construcción en que los cuadros los mantiene el Estado. Sino, ¿cómo los mantenés? No hablemos de otras épocas, donde nadie vivía del Estado, sino que trabajabas, estudiabas y militabas" (Jesús, dirigente FTV y legislador provincial, 23 jun. 2008).

Desde una preocupación similar, Lorenzo, dirigente nacional de la misma organización, elaboraba un balance de la FTV en sus primeros años (década del ochenta) y en el presente, identificando el problema de la profesionalización:

"Lorenzo: Crecimos cualitativa y cuantitativamente. [...] Y tenemos nuevos problemas, por ejemplo, cuando estábamos en la ruta y nadie tenía un cargo éramos todos felices, hoy que tenemos directores, subsecretarios, legisladores, concejales, se complejiza mucha más la relación entre nosotros.

Dolores: ¿Por qué se complejiza?

Lorenzo: Porque hay mucha derrota cultural y porque nosotros no estamos exentos de esa derrota cultural, somos parte de esta sociedad. Es un compañero que no tenía nada y ahora tiene un espacio de poder político" (Lorenzo, dirigente nacional de la FTV, 12 mar. 2008). 
La nostalgia sobre el perfil del militante del pasado, previo a la llegada de estas organizaciones al Estado, también emanaba de la reflexión de Santino (33 años), funcionario municipal y referente de una organización territorial pequeña local en el sudeste del conurbano vinculada a un intendente del PJ, que manifestaba preocupación por el impacto que la llegada al Estado y la consiguiente disponibilidad de cargos había tenido sobre el compromiso y la pertenencia de los militantes:

"Pienso que en términos de práctica militante hemos desacumulado. Porque el tiempo que nos tomó aprender a acumular de este lado, en el caso de algunos compañeros en particular, encontrarse de golpe al frente de la acción de masas, compañeros que habían sido dirigentes universitarios, que estaban al frente de una fotocopiadora de la UBA [Universidad de Buenos Aires] y ahora están al frente de una Secretaría de Estado nacional, y tienen una estructura comunicacional oficial que alimenta sus organizaciones y las dinamiza, y las vigoriza, encontrarse de pronto frente a ese fenómeno de masas desde el Estado es como haberse catapultado muy velozmente a un lugar de conducción de masas. Si no se va consolidando un proceso de militancia y todos los que se incorporan no van internalizando una cantidad de valores, de disciplinas organizativas, es lo que me lleva a mí a la conclusión de que hemos desacumulado. Hemos tenido capacidad de llegar más pero peor. Por eso la conclusión es que no tenemos una estructura intermedia. Digo, cuando nosotros empezamos a militar, cuando no teníamos vinculación con el Estado, muy difícilmente un compañero de nuestra agrupación se iría. Era muy difícil, pero teníamos un muy bajo índice de deserción" (Entrevista con Emilio y Santino, militantes de organización sindical y organización territorial, respectivamente, ambas vinculadas a intendente de zona sudeste del conurbano bonaerense, 13 nov. 2013).

Como ya fue afirmado, en cambio, en las organizaciones argentinas nacidas durante los gobiernos kirchneristas y ya fundadas como parte del oficialismo, la posibilidad, durante el kirchnerismo, de una inserción estatal de sus miembros no estaba antecedida por un legado de desarrollo organizativo por fuera de ese vínculo, y previo a él, con lo cual este tipo de nostalgia no se observaba con frecuencia en los testimonios recogidos, aunque sí aparecía de modo implícito en sus testimonios (y sin nostalgia) el fenómeno de profesionalización.

Era, por otro lado, entre los entrevistados del PT, en Brasil, donde la descripción nostálgica del militante no profesionalizado del pasado devenía un punto central. La descripción del militante de los años de formación del partido, que no cobraba un salario - estatal o partidario -, sino que incluso contribuía al financiamiento del partido - a través de la cotización (contribución monetaria) de los afiliados, la cual hoy aún existe pero ha disminuido y ha sido reformada en su implementación a los distintos tipos de afiliado ${ }^{25}$ - y que desarrollaba su militancia en el tiempo libre (con reuniones por las noches, los fines de semana, etc.), era contrapuesta por los entrevistados con el fenómeno actual de militantes "institucionalizados", "profesionalizados" o "burocratizados". Así, Breno, dirigente sindical de la CUT-RJ y militante (o simpatizante, en sus palabras) de la corriente mayoritaria del PT (Articulação, luego denominada Construindo um Novo Brasil o CNB), decía:

Tuvimos un período, en los primeros años del PT, en que no había esa figura del militante profesional. Fue algo que vino después. Los dirigentes del partido se profesionalizaron [...] en ese primer período íbamos a las reuniones del partido cuando salíamos del banco [donde él trabajaba], el otro trabajaba todo el día como médico, el otro en la fábrica. Otro, abogado, se quedaba todo el día en el estudio y nos reuníamos de noche. Y prácticamente los militantes no teníamos fin de semana libre. Las conferencias, los encuentros, las charlas, los debates hoy cambió completamente eso. Hoy el partido está en el poder. Desde mi punto de vista se institucionalizó excesivamente. El PT mantenía relaciones estrechas con los movimientos sociales, como si fuera la marca distintiva del partido, y hoy se alejó de eso. Creo que, hasta como una cuestión de supervivencia política, [el 
${ }^{26}$ Aunque no de modo tan reiterado como en el PT, entrevistados del PDT y del PCdoB también advertían sobre el proceso de profesionalización y sus efectos perniciosos. Ezequiel, dirigente local del PDT-RJ (cercano a los 30 años) consideraba que el militante con un vínculo laboral veía limitada su autonomía para hacer críticas a las direcciones partidarias (Ezequiel, dirigente local del PDT-RJ, 20 ago. 2013).

${ }^{27}$ Gurgel (1989) analizaba el fenómeno, muy común en el PT desde sus inicios, de simpatizantes del partido que votaban, hacían campaña por sus candidatos y, sin embargo, no se afiliaban, pero se consideraban dentro del partido o "se reivindicaban petistas" (defendiendo las posiciones del PT cuando éstas coincidían con sus posiciones personales). partido] va a tener que hacer ese camino de vuelta (Breno, militante de la CUT de Río de Janeiro y de CNB-PT, 3 set. 2013).

Y, Fabiano, entrevistado petista ya mencionado, se refería, con la noción de "distorsión", al fenómeno común de aquellos petistas que dependían de la militancia para sobrevivir económicamente, que habían hecho gran parte de su vida "trabajando" como militantes, no habiendo podido formarse o desarrollar otras ocupaciones, y que acababan preocupándose sobre todo por cómo iban a reproducir su vida y, para ello, su espacio político institucional, que era su trabajo. En sus palabras "hoy todo el mundo quiere estar profesionalizado" ${ }^{26}$.

Leonel y Enrique, también ya citados, describían, por su parte, el problema de la profesionalización en relación con las campañas electorales petistas, factor que desemboca en la segunda dimensión de nostalgia que analiza este artículo, la de las condiciones de la militancia. Para ambos entrevistados, la campaña constituía un momento paradigmático para observar el proceso de profesionalización de la militancia en el PT. Considerando que la campaña presidencial de 1989 de Lula había sido la "última que de hecho involucró una militancia de izquierda sin la profesionalización que vino después", y postulándose él mismo como un ejemplo de militante que había hecho campaña de modo voluntario desde fines de los ochenta y de modo remunerado desde 1998, Enrique coincidía con Leonel en la existencia de una diversidad de situaciones coexistentes dentro de ese fenómeno de campañas profesionalizadas: desde el militante involucrado con el partido de modo permanente que recibía un ingreso durante la campaña, los simpatizantes no afiliados, hasta personas absolutamente desvinculadas en términos ideológicos o afectivos con el partido y contratadas, con un contrato laboral temporario (sin derechos laborales), para repartir material de campaña en las calles. Ese abanico de situaciones era cubierto bajo la figura legal del cabo eleitoral. El ejemplo más ostensible de ese proceso de profesionalización de las campañas era, según ellos, el de los informalmente denominados moranguinhos (frutillitas) en la campaña municipal de Marta Suplicy por su reelección como intendenta [prefeita] de la ciudad de San Pablo en 2004, comicios en los que fue luego derrotada. Se trató, entonces, de una enorme y exhaustiva estructura de contratados, con una suerte de uniforme (remera, gorra, etc.) que recorrían las calles de la ciudad. Según Leonel, "algunos moranguinhos hasta podían ser petistas, pero eso causó un gran impacto en los simpatizantes del PT". Esos simpatizantes serían, para el entrevistado, los que más han desaparecido en los últimos años. ${ }^{27}$

La nostalgia referida a esta primera dimensión, que de algún modo se revestía de una suerte de autocrítica del propio partido, aparecía con más fuerza en los testimonios de la militancia petista que en otros partidos de la base del gobierno, en los que los relatos apuntaban más bien a otra dimensión, que será analizada a continuación.

\section{b) Condiciones en las que se milita: el contexto ayer y hoy}

Las características asociadas al modo de hacer campaña electoral, entonces, son parte de la nostalgia presente en los testimonios respecto de las condiciones en las que se militaba en el pasado. Incluso entrevistados de la base oficialista por fuera del PT, como Ezequiel, dirigente local del PDT-RJ ya mencionado, describían las campañas actuales de modo similar, como muy determinadas por los publicistas [marketeiros], profesionalizadas, con empleados pagos haciéndolas y con pocos "resquicios de militancia espontánea" (20 ago. 2013). Con un diagnóstico similar, Felipe, dirigente local del PCdoB en Río de Janeiro (56 años), manifestaba que

"En los años ochenta, las campañas eran mucho más fuertes. El compromiso político era mayor. Una persona se dedicaba mucho, gastaba dinero de su propio bolsillo. Yo mismo contribuía mucho más que ahora. Hoy es poco lo que las per- 
${ }^{28}$ Un ejemplo del problema de la disponibilidad de recursos es el descripto por Gonzalo (36 años), dirigente de una agrupación local del PJ, que afirmaba "en el año '87 en mi barrio nosotros abríamos un local en una casa o garaje y éramos toda la cuadra militando. Y enfrente había otras dos unidades básicas (UBs). Hoy vos tenés tu unidad básica y si al otro tipo no le bajan oxígeno para trabajar, los recursos, o la plata, no la abre" (27 sep. 2007).

${ }^{29}$ En los años de formación del PT, los núcleos de base empezaron como pequeños grupos de personas que podían organizarse por barrio, por lugar de trabajo, por categoría de trabajo, o por movimiento social. Gurgel (1989) definía los núcleos como órganos de base en los que, en teoría, se sonas dan de contribución [monetaria] al partido. Antes, la campaña era algo muy en la calle, con venta de prendedores, etc. Hoy la campaña es la acción de una empresa, es más de clase media, y es mucho más cara" (Felipe, dirigente local del PCdoB-RJ, 23 ago. 2013).

Como se anticipaba antes, de todos modos, esa nostalgia respecto del contexto en el que se desarrolla la militancia no era sólo recurrente entre los entrevistados brasileros, sino que también se advertía entre los argentinos. En relación con los rasgos de las campañas electorales en Argentina, Héctor (militante de Kolina al momento de la entrevista, ya citado en este artículo), que recordaba haber militado para el PJ incluso antes de tener edad suficiente para afiliarse, señalaba que "ahora vos ves que están pintando paredes, y son empresas que pintan. En ese momento [1983] éramos los militantes que salíamos [...] salíamos de noche con camionetas, éramos como veinte, pintábamos paredes, los actos eran multitudinarios". Martín, dirigente de una agrupación menor del PJ de La Matanza y funcionario municipal (mayor de 40 años), sostenía que "en sí cambió mucho la militancia. Antes el militante era el que caminaba, el que salía a hacer las pintadas. Ahora está como más organizado, y divididas las tareas. A mí me gustaba más lo de antes” (27 sep. 2007). Por su parte, Javier (48 años), otro militante del PJ local (de la Agrupación Ramón Carrillo, la mayor del distrito) consideraba que las pintadas callejeras habían dejado de ser una "herramienta publicitaria importante", que se había convertido en una demostración de tamaño propio y de la inserción en los barrios y que terminaba contando sólo para el "ambiente electoral", incluidos los adversarios políticos (primera entrevista con Javier, 3 ago. 2007).

Además del modo de hacer campaña, las apelaciones nostálgicas de los entrevistados de ambos países referidas a las condiciones en las que se militaba identificaban otros fenómenos actuales: el deterioro de los espacios de militancia (ello, especialmente entre los miembros del PT); problemas relacionados con la dependencia respecto de recursos estatales para militar - cuestión vinculada con la de la profesionalización, que ya ha sido analizada, y que se advertía bastante entre miembros de las organizaciones sociales preexistentes al kirchnerismo ${ }^{28}$-; la centralidad, en Brasil, de figuras con alta popularidad o con mandatos legislativos por sobre los militantes (vínculos con la ciudadanía carentes de la intermediación militante, por ejemplo, y demasiada autonomía de los legisladores - entendidos en un sentido amplio, nacionales, provinciales y municipales); la proliferación de afiliados que mantenían con el partido u organización un vínculo muy superficial y frágil (en el PT); dinámicas de funcionamiento del oficialismo definidas por la incertidumbre, la inorganicidad y los vínculos radiales (en ambos casos nacionales, pero especialmente entre los entrevistados del PJ); el disminuido peso de las identidades partidarias y la volatilidad del comportamiento electoral de la ciudadanía, etc. Aunque no serán examinadas aquí todas estas subdimensiones, cabe, para terminar, dedicarnos a una de ellas.

La lectura de un proceso de deterioro de los espacios de militancia desde los años noventa tenía una gravitación notoria en las entrevistas a miembros del PT. Ello especialmente en relación con la figura de los núcleos, instancias de base propias del partido desde sus años pre-fundacionales, durante la dictadura. ${ }^{29}$ Secco (2011) releva, para 1982, cerca de 1000 núcleos en todo el país y 28.000 afiliados involucrados en los mismos. ${ }^{30}$ Los núcleos fueron, casi desde el principio, motivo de mucho debate dentro del partido: cuánto poder de influencia debían tener (por ejemplo, si podían elegir delegados para ir a los Encuentros del partido) y cómo quitarles o asignarles poder podía derivar en una fuga de militantes. Según Enrique, militante histórico paulista ya mencionado, los núcleos sufrieron, en la década del noventa, y con el ascenso del poder de los legisladores (todos aquellos con un mandato legislativo a nivel 
discutían las posiciones y propuestas para luego llevar a las instancias de encuentro más amplias del partido. ${ }^{30}$ Amaral (2010b), por su parte, habla de más de 26.000 afiliados ligados a 632 núcleos de base para mayo de 1980, distribuidos entre 23 estados.
${ }^{31}$ En 20 ciudades del Estado de San Pablo había sólo un núcleo por ciudad. Las ciudades con más núcleos eran Diadema, Mauá y San Pablo (68, 48 y 28 , respectivamente) El resto tenían entre dos y cuatro por ciudad (14 ciudades) (Amaral, 2010b). nacional, estadual o municipal) dentro del partido, un proceso de desvirtuación, con una inflación o "hinchamiento" que no tenía un correlato de vida interna activa o militante: crecían indiscriminadamente en número de afiliados, de modo de poder sus conducciones elegir más delegados para los encuentros partidarios, lo cual luego derivó en la quita de esa atribución por parte de la dirección del partido. Otro entrevistado, Fabiano, ya mencionado, hablaba de núcleos dispersos, que ya no funcionaban como antes, que se habían disuelto o permanecían como una mera formalidad. Los relatos de Virgílio, Baltasar y Salomé tenían una orientación similar:

"Antiguamente había núcleos, estaban los periódicos del PT, que eran como organismos de reunión, tenían una vida muy activa, muy activa. Hoy no hay nada. Las direcciones regionales [direcciones por región, por barrio] son un chiste, no funcionan. [...] Entonces el PT es una inmensa cáscara vacía en tanto estructura orgánica. La dirección nacional, la dirección estadual, la dirección municipal, que funcionan mal, al menos funcionan. Son instancias de poder. Pero no hay vida orgánica de debate entre la militancia (Virgílio, militante histórico del PT de Río de Janeiro, 23 jun. 2009).

"Hasta la década del noventa había una vida común entre las tendencias en los núcleos de base, de hacer un debate político desde la situación del barrio hasta la dirección nacional. Eso cambió mucho" (Segunda realizada a Baltasar, dirigente del PT en Río de Janeiro, tendencia Democracia Socialista, 23 jun. 2009).

"El problema es que el PT antes tenía una vida interna muy rica, tenía debate, tenía núcleos, que muchas veces eran organizados por grupos más a la izquierda. Y la gente, vamos a decir, más de derecha, era oriunda más del movimiento sindical, de la iglesia. ¿Qué pasa? Para ganar a esos grupos de izquierda, se utilizó una práctica que, la verdad, es más parecida a las de los partidos más burgueses, que es que vos llenás el ómnibus, afiliás a la gente, llevás a votar en la convención a personas que no tienen ninguna vinculación con el partido. [...] Y de esa forma es que ganaron el control absoluto del partido. Sólo que eso provocó un efecto secundario, que fue matar la vida interna del partido. [...] si hoy vas a buscar cuál es el núcleo del PT que hace discusiones, que hace debates, ninguno, o tenés uno o dos. Es un desierto. [...] Aquel factor que se decía antiguamente, esa historia de "ah, el PT, la militancia del PT hace la diferencia", eso ya no existe más. Lo que pasa es que Lula creó un vínculo directo con la población, se unió con el elector de esa forma. Pero aquella cosa del militante de puerta en puerta, eso se acabó" (Salomé, afiliado y ex militante petista en Río de Janeiro, 16 jun. 2009).

Estas caracterizaciones de los entrevistados se condicen con algunos estudios sobre lo ocurrido con los núcleos. Citando una encuesta realizada por la Fundación Perseu Abramo con delegados del partido en el 3er Congreso Nacional del PT en 2007, Amaral (2010b) afirma que el 76,9\% de éstos consideraba ya entonces que los núcleos habían perdido peso político paralelamente al crecimiento del partido. En la enumeración que el autor hace, con datos provistos por el propio PT, de la cantidad de núcleos de base del partido que había en cada ciudad en el Estado de San Pablo en 2010, podemos advertir que los núcleos habían dejado de ser grupos por barrio o lugar de trabajo, como lo eran en los años ochenta. ${ }^{31}$ Ello refuerza el diagnóstico de los propios entrevistados.

En Brasil, entonces, la nostalgia respecto de las condiciones en las que se desarrollaba, en el pasado, la militancia, remitía a una imagen de la propia vida organizativa y partidaria dentro del PT. Aunque no estaba ausente la referencia a un contexto más general, la idea que prevalecía era la de un deterioro de la dinámica partidaria y una caída en la intensidad de la militancia - relacionada con el funcionamiento de los núcleos, con el tipo de vínculo de los afiliados al partido, con la incidencia de la llegada al Estado sobre la actividad militante, etc. 
Es llamativo, en este punto, el contraste con los testimonios del PJ, en los cuales, aunque se hallaron algunas referencias al desprestigio del propio partido en esos años, había una significativa ausencia en las narrativas sobre el pasado. Mientras que entre los militantes del PT abundaban espontáneamente las descripciones y análisis sobre las transformaciones sociales más amplias durante los años noventa y las reformas que había experimentado el propio partido en su interior, la omisión de esos procesos para el caso argentino era muy clara. Los entrevistados del PJ, comúnmente se limitaban a insinuar contrastes con el pasado en términos del nivel general de compromiso y participación, sin aludir a las transformaciones sufridas por el partido y por la propia sociedad argentina durante el menemismo. ¿Acaso esa omisión se debía a que muchos de ellos habían vivido esos 10 años siendo también oficialistas, es decir, apoyando aquellas políticas de gobierno que habían perjudicado, por ejemplo, a la histórica base social del partido, los trabajadores? Lo cierto es que la cuestión de las transformaciones previas del propio partido y el origen de las mismas era un tema recurrente en los relatos de los petistas, mientras que estaba ausente en los entrevistados justicialistas

En el caso argentino, entonces, el énfasis de las apelaciones nostálgicas estaba puesto en un pasado recordado (o imaginado) como un momento en que las reglas informales o la lógica del juego partidario y electoral tenía un carácter más previsible y no tan disociado del mundo de la militancia (por ejemplo, en el proceso de selección de candidatos para componer la oferta electoral). Ello, en contraste con un presente en el que primaría la incertidumbre de los escenarios políticos para el mediano y largo plazo, y la volatilidad, no sólo en el comportamiento del electorado, sino también en los alineamientos o posiciones de los propios dirigentes políticos y sus bases organizadas, como veíamos al inicio en el testimonio de Salvador sobre la fluctuación de las propias redes militantes o, también, como ilustraba dramáticamente Maxi (33 años), militante de la agrupación Ramón Carrillo en el PJ de La Matanza, al decir “en política, un año al compañero lo tenés acá, otro lo tenés en la vereda de enfrente, y al otro año lo volvés a tener con vos" (29 nov. 2007). Un escenario en el que los partidos ya no parecerían importar del mismo modo que antes o, incluso, su imagen se veía erosionada ante el electorado. En este sentido, algunos de los entrevistados del PJ se referían un desprestigio del partido desde los noventa (en parte, debido a las políticas de los gobiernos de Carlos Menem - aunque muchos de ellos reconocían haber militado al interior del partido en aquel período bajo el liderazgo de aquel) y a la necesidad de recuperar la vinculación afectiva histórica con la población. Incluso, se advertían instancias de militancia partidaria debilitadas y candidatos desprendidos de sus propios partidos como un fenómeno más y más común. En palabras de Vicente,

"La falta de discusión interna, y la falta de democracia interna de partidos políticos hacen que los que no pueden tener un canal de expresión se formen su propio partido, también. Eso puede ser que sea un partido que no exista, o un partido que tenga mucha más influencia electoral, también. Eso también, detrás de un dirigente que tenga una cuestión mediática detrás [...] Hoy un tipo que mide bien [en las encuestas], para qué se va a venir a embarrar los zapatos en la cancha de la política tradicional o del partido si sabe que puede llegar a perder una interna. [...] Los comités, las unidades básicas, en lugar de ser lugares de discusión de ideas, de proyectos, de problemas con el vecino, de discutir muchas veces teóricamente qué se piensa del barrio, qué se piensa de la ciudad, termina siendo un centro de jubilados en el cual se distribuye la caja de comida para fin de mes para los jubilados" (Vicente, dirigente sindical y del PJ en la ciudad de Buenos Aires, 5 abr. 2010). 


\section{Conclusiones: la nostalgia y sus significados}

Se ha argumentado aquí que las apelaciones nostálgicas analizadas en este trabajo constituyen una de las dos caras de un doble fenómeno - de adaptación y nostalgia - advertido al interior de la militancia oficialista en Argentina y Brasil desde los gobiernos de Kirchner y Lula. Ese doble fenómeno puede ser atribuido al impacto que las condiciones de fluctuación en las identidades políticas y otras transformaciones en el formato de representación han tenido sobre la militancia.

En otros términos, mientras que la militancia política ha experimentado una adaptación a esas condiciones de volatilidad, en los testimonios de los actores se perfilan también distintas referencias al pasado cargadas de nostalgia o de saudade. Este último término portugués da cuenta de esa nostalgia o añoranza también como referida a algo que posiblemente nunca haya existido. Márcia (47 años), dirigente local del PT en San Pablo (presidenta de un "Directorio Zonal") ilustraba el peso de esa nostalgia entre la militancia petista con la imagen de un "rescate afectivo" que era ya típico en el partido (24 ene. 2014).

Como hemos visto, la presencia de esa nostalgia no era homogénea en ambos casos, ni entre las distintas organizaciones. A partir del agrupamiento de distintas categorías creadas en el propio proceso de análisis cualitativo de las entrevistas - a medida que se percibían regularidades en los testimonios - se identificaron dos dimensiones de esa nostalgia: las apelaciones al militante del pasado (su nivel de compromiso, su carácter voluntario y no profesionalizado y su formación política), por un lado, y la referencia al contexto o condiciones en que se militaba, por el otro.

Mientras que ambas dimensiones aparecían con fuerza en los testimonios brasileros, era la segunda dimensión la que predominaba entre los entrevistados argentinos. Y es que, en líneas generales, la referencia nostálgica apuntaba, en este caso, más bien a un pasado de identidades partidarias arraigadas, mientras que en Brasil, el pasado al que esas apelaciones aluden era el período formativo del propio PT. ¿Qué había detrás de esos contrastes y énfasis diferenciados?

Por supuesto, las generaciones de militantes (en términos etarios pero también en términos de momento de afiliación o inicio de la carrera militante) eran elementos significativos a la hora de delimitar esos contrastes. Después de todo, ¿cuánta nostalgia podría portar un joven militante afiliado al PT durante el segundo de gobierno de Lula, cuando las transformaciones partidarias ya se habían desplegado? Pero ese ingrediente más elemental debe ser complementado con otros argumentos y factores que contribuyen a una comprensión más profunda del fenómeno.

Para los entrevistados de organizaciones oficialistas nacidas al calor del propio ciclo de gobiernos kirchneristas (y varias de ellas, incluso, en los últimos años de ese ciclo), el peso marginal de referencias de carácter nostálgico se hace inteligible en el marco de un rescate absoluto no del pasado sino del presente (2003-2015), que era leído en clave de reflorecimiento de la militancia. O incluso de modo más amplio, como lo ha advertido González (2015) en su propio trabajo de campo con militantes kirchneristas en la ciudad de Bahía Blanca (distrito en el sur de la provincia de Buenos Aires), como un "resurgimiento de la política" (González, 2015: 77). Es decir, mientras que en Brasil muchos entrevistados petistas contaban con un pasado de militancia en los años ochenta especialmente valorado por su riqueza e intensidad (subjetivamente, por ellos mismos, pero también en los estudios académicos que han abordado aquel período del PT), en la narrativa de las nuevas organizaciones kirchneristas, lo ocurrido en Argentina habría tenido una evolución inversa. El kirchnerismo habría generado, en su visión, una reactivación y multiplicación 
del universo militante (aunque ello no fuera en las mismas condiciones que al momento de la redemocratización), vista con entusiasmo después de años de desencantamiento con la política electoral.

Pero, además, el propio formato o configuración de estas organizaciones debería ser tomado en cuenta para explicar el contraste respecto de la nostalgia sí advertida en los testimonios del PT y del PJ. Además de un origen relativamente reciente, ¿qué nostalgia posible habríamos de encontrar, respecto de un pasado de partidos con arraigo en la sociedad y capaces de configurar identidades estables, en organizaciones militantes que no eran, ellas mismas, construcciones partidarias? Aunque movilizaran símbolos peronistas, estas organizaciones no se estructuraron como partidos (con padrones de afiliados, inscripción ante la justicia electoral, elecciones internas, etc.), sino que se reivindicaban como parte del "movimiento peronista", pero no del PJ. En estas organizaciones, entonces, los testimonios referidos a un electorado volátil (que en una elección podía apoyar al kirchnerismo y, en la siguiente, repudiarlo) no lo registraban como resultado de la desagregación partidaria o de un deterioro de las identidades partidarias, sino más bien como fruto de un error de comprensión de los votantes (manipulados por los medios de comunicación masiva, por ejemplo) o incluso de cierta ingratitud (la incapacidad de ver lo que el gobierno les había dado o garantizado en sus propias vidas).

Para los entrevistados de las redes locales del PJ, en cambio, aunque hubiera signos también de una reivindicación del presente, ésta no podría revestirse del mismo carácter absoluto mencionado más arriba. Si lo hiciera, entonces ¿qué lugar quedaría para la propia trayectoria del PJ, organización de pertenencia de esos militantes, durante los años ochenta y noventa? Para quienes se iniciaron políticamente en aquellos años y luego continuaron en el partido, ello equivaldría a negar sus propias carreras militantes en el justicialismo. Y para los militantes más jóvenes, implicaría suprimir el legado partidario. Sin duda, en los testimonios del PJ estaba implícita cierta incomodidad con la etapa de militancia oficialista menemista, sobre la cual había escasísimas menciones espontáneas. Pero sí se referían con regularidad a un pasado con mejores condiciones para militar, y en el cual la identidad partidaria parecía gravitar de otro modo en la ciudadanía.

En el caso de la militancia del PJ, además, la nostalgia operaba como un vehículo indirecto de la disconformidad por el lugar que el gobierno les había asignado dentro de sus bases de sustentación activa, es decir, dentro del conjunto oficialista y por la coexistencia, primero (2003-2007) con organizaciones provenientes de la protesta piquetera y luego (especialmente desde 2009-2010) con organizaciones recientes y rápidamente reposicionadas dentro del kirchnerismo, como La Cámpora. Aunque el peronismo históricamente haya tenido más bien un formato y dinámicas movimientistas (y no las de un partido clásico), no era ese perfil el que resaltaban en sus definiciones estos entrevistados del PJ. En cambio, optaban por una descripción del estado de desorganización y disgregación del partido a nivel nacional y provincial durante el kirchnerismo identificándolo como un problema asociado al propio período y a las estrategias de construcción política y de alianzas del gobierno. Es desde esa lectura que los entrevistados justicialistas de La Matanza ungían al PJ de su propio distrito (es decir, al PJ local) como un bastión desde el cual defender y recuperar ese "hogar perdido" - si tomamos la definición de nostalgia esbozada al inicio de este trabajo - que había sido el peronismo nacional en el pasado.

Ahora bien, es entre quienes tenían una inscripción actual en una organización por fuera del PJ pero habían tenido un paso por éste en el pasado donde se observaba caracterizaciones heterogéneas. Por un lado, testimonios similares en algunos aspectos a los de militantes del PJ, con manifestaciones nostálgicas 
respecto del contexto e incluso, en algunos casos, respecto del perfil del militante mismo, su compromiso, formación, etc. (algo parecido, incluso, a lo observado en algunas organizaciones sociales que se habían sumado al oficialismo durante el gobierno de Néstor Kirchner y que venían de trayectorias de protesta social). Por otro lado, otro grupo de entrevistados expresaba un marcado rechazo a aquel pasado de los años ochenta y noventa, probablemente por lo que éste había significado para ellos personalmente (desencantamiento, frustración e incluso abandono de la militancia político-electoral). Estos últimos testimonios, entonces, se inscribían más en el tipo de planteo esbozado desde las organizaciones como La Cámpora, MUP y otras nuevas, a la que esos entrevistados, con experiencias previas en el PJ, parecían, así, haberse asimilado más plenamente.

En la intensa nostalgia de los entrevistados brasileros respecto de la militancia petista de los primeros años de actuación del partido y hasta mediados de los noventa, emergen distintos elementos.

Pollak y Heinich (1986) han afirmado que el testimonio pone en juego tanto la memoria como la reflexión sobre sí mismo por parte del sujeto, es decir, su propia identidad. Siguiendo esa idea, podemos interpretar la nostalgia de los militantes petistas en tanto intento de reafirmación y legitimación de su identidad, delimitándose respecto de las contradicciones del presente. Al añorar en voz alta aquello que el PT había sido, era como si ellos mismos no hubieran cambiado junto con el partido y portaran aún un resabio de esa militancia intensa, rica y arraigada (aunque ello fuera sólo en la forma de un recuerdo valorizado). En otros términos, era como si afirmaran "no somos esto en lo que el PT se ha convertido, sino que aún nos constituye como militantes la esencia de lo que el PT supo ser en su primera década de existencia, y eso define nuestra identidad".

La nostalgia o "rescate afectivo" les permitía, entonces, canalizar las frustraciones y tensiones propias de haberse convertido en un partido volcado al Estado, al ámbito institucional y a gobernar. Y era a través de esa nostalgia que los militantes podían constituirse como articuladores entre un pasado consolidado en su carácter (en términos de lo que el PT representaba) y un presente en riesgo, especialmente en un contexto en el que el PT había ido perdiendo aquellos rasgos que lo distinguían anteriormente del resto del espacio partidario. Un presente en el que entre los propios entrevistados se revelaba el temor a una "descaracterización” del partido (Vítor, 42 años, dirigente del PT en San Pablo, 19 sep. 2008), es decir, a que la identidad de éste acabara diluyéndose con el viraje ideológico y programático que había tenido lugar. Ese autoposicionamiento implícito como hilos conductores de la mano de la nostalgia evoca el análisis que Barros Pereira (2013) presenta del Bloco da Saudade en el carnaval de Pernambuco, cuyo objetivo habría sido precisamente "colocarse como mediador entre el ayer y el hoy actuando como hilo conductor que supuestamente garantiza la continuidad de un proceso histórico que amenaza con romperse" (Barros Pereira 2013, p.121; traducción propia). La nostalgia, entonces, puede funcionar como un intento de retener el pasado para intentar moldear el futuro. En términos de Boym (2001), "la nostalgia no siempre es sobre el pasado, puede ser retrospectiva pero también prospectiva. Las fantasías del pasado determinadas por las necesidades del presente tienen un impacto directo sobre las realidades del futuro" (Boym 2001, p.13; traducción propia).

Adicionalmente, aunque las manifestaciones de nostalgia aparecían en la gran mayoría de los militantes petistas entrevistados, era más acusada entre los que integraban corrientes partidarias por fuera del denominado "campo mayoritario" del partido, específicamente, por fuera de la CNB (Construindo um Novo Brasil, ex Articulação). La nostalgia, por ello, también operaba como un 
dispositivo de crítica a la corriente dominante, a la que se le atribuía el haber motorizado distintas reformas significativas sobre el modo de funcionamiento interno del partido y virajes en sus posiciones y políticas de alianzas desde mediados de los noventa.

El peso que adquieren las apelaciones nostálgicas entre los militantes del PT y su débil presencia entre los militantes kirchneristas de organizaciones surgidas a lo largo del período analizado y por fuera del PJ da cuenta, por último, de modos disímiles de experimentar los procesos políticos contemporáneos.

En el primer caso, aunque la identificación con el gobierno (sus políticas de transferencia de renta, la reducción de la pobreza, etc.) y su defensa estaban fuera de duda, la nostalgia sobre otra época del partido estaba también expresando una frustración con la coyuntura política de un PT gobernante, con un contexto político distante de las aspiraciones que muchos de ellos habían tenido al empezar a militar. Nuevamente aquí el pasado es revisitado a partir de las preocupaciones sobre el presente o, en los términos de la sugerente reflexión de Boym (2001), la nostalgia no por un estado o situación acabada sino también por los sueños irrealizados de ese pasado, y las visiones de un futuro que han devenido obsoletas (Boym 2001, p.13).

En el segundo caso, en cambio, el ciclo kirchnerista era ungido por los militantes como un giro inesperado y que había trascendido ampliamente sus expectativas sobre la política, percibiéndose escasos matices o reparos respecto de los límites o contradicciones de ese proceso.

A futuro, con el kirchnerismo ya fuera del gobierno nacional (aunque sí gobernando algunas provincias y municipios), queda por ver y comprender qué perfil, expresiones, modalidades de acción y narrativas sobre el ahora pasado reciente serán asumidas por sus organizaciones militantes. En Brasil, los meses previos a la suspensión de la presidenta Dilma Rousseff (en un proceso que ha sido denunciado como un golpe institucional) mostraron cierta reactivación militante en las manifestaciones en defensa del gobierno. Consumada ya la maniobra opositora, con la destitución de Rousseff, futuros estudios deberán abocarse a analizar una militancia petista (y de la CUT, el PCdoB, y otras organizaciones aliadas) fuera del Estado federal, y determinar si se presenta más volcada a las calles y tal vez reducida, aunque depurada y vigorizada.

María Dolores Rocca Rivarola (doloresrocca@gmail.com) es Investigadora del Consejo Nacional de Investigaciones Científicas y Técnicas (CONICET), con sede de trabajo en el Instituto de Investigaciones Gino Germani (IIGG), de la Universidad de Buenos Aires (UBA). Es Doctora en Ciencias Sociales por la Universidad de Buenos Aires (UBA), Licenciada en Ciencia Política (UBA) y docente de Historia Contemporánea en la Facultad de Ciencias Sociales de la misma universidad. Vinculación Institucional: Facultad de Ciencias Sociales, UBA, Ciudad de Buenos Aires, Argentina.

\section{Referencias}

Aboy Carlés, G., 2001. Las dos fronteras de la democracia argentina. La reformulación de las identidades políticas de Alfonsín a Menem. Rosario: Homo Sapiens.

Altamirano, C., 2004. "La lucha por la idea": el proyecto de la renovación peronista. In M. Novaro \& V. Palermo, eds. La historia reciente. Argentina en democracia. Buenos Aires: Edhasa.

Amaral, O., 2010a. Adaptação e resistência: o PT no Governo Lula entre 2003 e 2008. Revista Brasileira de Ciência Política, 4 , pp.105-134.

, 2010b. As transformações na organização interna do Partido dos Trabalhadores entre 1995 e 2009. Tese de Doutorado. Campinas: Universidade Estadual de Campinas.

Balbi, F., 2007. De leales, desleales y traidores. Valor moral y concepción política en el peronismo. Buenos Aires: Antropofagia.

Balestrini, A., 2007. Declaración de Alberto Balestrini al Periódico Local UNO. Periódico local UNO, 3(33), abr.

Barros Pereira, M.I.D., 2013. Valores do passado: Tradição e nostalgia no Bloco da Saudade. Tese de Maestria. Recife: Universidade Federal de Pernambuco.

Boym, S., 2001. The Future of Nostalgia. New York: Basic Books. 
Carreirão, Y.S., 2008. Opiniões políticas e sentimentos partidários dos eleitores brasileiros. Opinião Pública, 14(2), pp.319-351. DOI: 10.1590/s0104-62762008000200003

Cheresky, I., 2006. La política después de los partidos. In I. Cheresk, ed. La política después de los partidos. Buenos Aires: Prometeo.

, 2007. Los desafíos democráticos en América Latina en los albores del siglo XXI. In I. Cheresky, ed. Elecciones presidenciales y giro político en América Latina. Buenos Aires: Manantial.

Craig, S.C., 1988. The Decay of Mass Partisanship. Polity, 20(4), pp.705-713. DOI: 10.2307/3234902

Delamata, G. \& Armesto, M., 2005. Construyendo pluralismo territorial. Las organizaciones de desocupados del Gran Buenos Aires en la perspectiva de sus bases sociales. In G. Delamata, ed. Ciudadanía y Territorio. Las relaciones políticas de las nuevas identidades sociales. Buenos Aires: Espacio.

Franco, M., 2007. Sentidos y subjetividades detrás del discurso: reflexiones sobre las narrativas del exilio producidas en entrevistas orales. Anuario de Estudios Americanos, 64(1), pp.37-62. DOI: 10.3989/aea.2007.v64.i1.32

Freire de Lacerda, A., 2002. O PT e a unidade partidária como problema. Dados, 45(1), pp.39-76. DOI: $10.1590 / \mathrm{s} 0011-52582002000100002$

González, G., 2015. Política y cotidianeidad: memorias del pasado reciente en Bahía Blanca (Argentina). Antípoda, 23, pp.65-85. DOI: 10.7440/antipoda23.2015.04

Greene, S., 2004. Social Identity. Theory and Party Identification. Social Science Quarterly, 85(1), pp.136-153. DOI: 10.1111/j.0038-4941.2004.08501010.x

Guidry, J., 2003. Not Just Another Labor Party. The Workers' Party and Democracy in Brazil. Labor Studies Journal, 28(1), pp.83-108. DOI: 10.1353/lab.2003.0024

Gurgel, C., 1989. Estrelas e borboletas, origens e questões de um partido a caminho do poder. Rio de Janeiro: Papagaio.

Gutiérrez, R.A., 2001. La desindicalización del peronismo. Política y Gestión, 2, pp.93-112.

Hochstetler, K. \& Friedman, E., 2008. Representação, partidos e sociedade civil na Argentina e no Brasil. Caderno CRH, 21(52), pp.47-66. DOI: 10.1590/s0103-49792008000100005

James, D., 2004. Doña María. Historia de vida, memoria e identidad política. Buenos Aires: Manantial.

Kinzo, M.D., 2005. Os partidos no eleitorado: percepções públicas e laços partidários no Brasil. Revista Brasileira de Ciências Sociais, 20(57), pp.65-81. DOI: 10.1590/s0102-69092005000100005

Lawson, K. \& Merkl, P.H., eds. 1988. When Parties Fail. Emerging Alternative Organization. Princeton: Princeton University Press.

Leiras, M., 2007. Todos los caballos del rey. La integración de los partidos políticos y el gobierno democrático de la Argentina 1995-2003. Buenos Aires: Prometeo.

Levitsky, S., 2003. Transforming Labor-Based Parties in Latin America. Argentine Peronism in Comparative Perspective. Cambridge, UK: Cambridge University Press.

Mainwaring, S., 1999. Rethinking Party Systems in the Third Wave of Democratization: The Case of Brazil. Stanford: Stanford University Press.

Mainwaring, S. \& Torcal, M., 2005. Party System Institutionalization and party System Theory after the Third Wave of Democratization. Working Papers. Notre Dame: Kellog Institute.

Manin, B., 1992. Metamorfosis de la representación. In M. dos Santos, ed. ¿Qué queda de la representación política? Caracas: Nueva Sociedad.

Montero, J.R. \& Gunther, R., 2002. Los estudios sobre los partidos políticos: una revisión crítica. Revista de Estudios Políticos, 118, pp.9-38.

Natanson, J., 2004. El presidente inesperado. Rosario: Homo Sapiens.

Navarro, A., 2007. Matrices y tipologías en el análisis cualitativo de datos: una investigación con relatos de oficiales carapintadas. In R. Sautu, ed. Práctica de la Investigación Cuantitativa y Cualitativa. Articulación entre la Teoría, los Métodos y las Técnicas. Buenos Aires: Lumière.

Paiva, D.; Braga, M.S.S. \& Pimentel Jr., J.T.P., 2007. Eleitorado e partidos políticos no Brasil. Opinião Pública, 13(2), pp.388-408. DOI: 10.1590/s0104-62762007000200007

Palermo, V., 2000. Como se governa o Brasil? O debate sobre instituições políticas e gestão de governo. Dados, 43(3), pp.521-557. DOI: 10.1590/s0011-52582000000300004

Palermo, V. \& Novaro, M., 1996. Política y poder en el gobierno de Menem. Buenos Aires: Editorial Norma.

Perón, J.D., 2006. Conducción Política. Buenos Aires: Instituto Nacional “Juan Domingo Perón” de Estudios e Investigaciones Históricas, Sociales y Políticas.

Pollak, M. \& Heinich, N., 1986. El testimonio. Actas de la Investigación en Ciencias Sociales, 62/63, pp.3-29.

Pousadela, I., 2007. Argentinos y brasileños frente a la representación política. In A. Grimson, ed. Pasiones nacionales. Política y cultura en Brasil y Argentina. Buenos Aires: EDHASA.

Pousadela, I. \& Cheresky, I., 2004. La incertidumbre organizada. Elecciones y competencia política en Argentina (1983-2003). In I. Cheresky \& I. Pousadela, eds. El voto liberado. Elecciones 2003: Perspectiva histórica y estudio de casos. Buenos Aires: Biblos.

Power, T., 2008. Centering Democracy? Ideological Cleavages and Convergence in the Brazilian Political Class. In T. Power \& P. Kingstone, eds. Democratic Brazil Revisited. Pittsburgh: University of Pittsburgh Press.

Rocca Rivarola, D., 2012. ¿Partido oficial o actor relegado? El PJ y el PT durante el gobierno de Néstor Kirchner y Luiz Inácio Lula da Silva. In I. Cheresky \& O. Dabene, eds. Ciudadanía y representación política. Argentina en perspectiva 
comparada. ParisL OPALC/Centro de Estudios Políticos (CEP). Disponible en: http://www.centrodeestudiospoliticos.org/wp-content/uploads/2011/08/264tica1.pdf

, 2013. Relaciones y definiciones de pertenencia en los conjuntos oficialistas o bases de sustentación activa de Lula

(2002-2006) y Kirchner (2003-2007): Principales argumentos. Revista Temas y Debates, 26(17), pp.39-75.

,2015a. 'De Néstor y Cristina. De Perón y Evita'. Reflexiones sobre lo acontecido con la militancia kirchnerista y la identidad peronista desde 2003 hasta hoy. Revista SAAP, 9(1), pp.143-172.

,2015b. Vínculos y formas de la militancia oficialista. Un modo de adaptación a las condiciones de fluctuación política en Argentina y Brasil. Papeles de Trabajo, 15(9), pp.170-198.

Rocha, D.C., 2009. Jeunes du Parti des Travailleurs et crise du militantisme. Agora Débats/Jeunesses, 2(52), pp.89-104. DOI: 10.3917/agora.052.0089

Russo, S., 2014. Fuerza Propia. La Cámpora por dentro. Buenos Aires: Debate.

Samuels, D., 2004. From Socialism to Social Democracy: Party Organization and the Transformation of the Workers' Party in Brazil. Comparative Political Studies, 37(9), pp. 999-1024. DOI: 10.1177/0010414004268856

- 2008. A evolução do petismo (2002-2008). Opinião Pública, 14(2), pp.302-318. DOI: 10.1590/s0104-62762008000200002

Santos, F. \& Vilarouca, M.G., 2008. Political Institutions and Governability from FHC to Lula. In T. Power \& P. Kingstone, eds. Democratic Brazil Revisited. Pittsburgh: University of Pittsburgh Press.

Sautu, R., 1999. El método biográfico. Buenos Aires: Editorial de Belgrano.

Schuttenberg, M., 2011. La reconfiguración de las identidades 'nacionales y populares'. Los puentes discursivos para la inserción de tres tradiciones políticas en el espacio 'transversal kirchnerista'. Revista Sociohistórica del CISH, 28, pp.41-73.

Secco, L., 2011. História do PT. Granja Viana: Ateliê Editorial.

Singer, A., 2012. Os sentidos do lulismo. Reforma gradual e pacto conservador. São Paulo: Companhia das Letras.

Svampa, M., 2009. Introducción. In M. Svampa, ed. Desde abajo. La transformación de las identidades sociales. Buenos Aires: Biblos.

Svampa, M. \& Pereyra, S., 2003. Entre la ruta y el barrio. La experiencia de las organizaciones piqueteras. Buenos Aires: Biblos.

Vázquez, M., 2014. Bringing militancy to Management: An Approach to the Relationship between Activism and Government Employment during the Cristina Fernández de Kirchner Administration in Argentina. Apuntes, XLI(74), pp.67-97.

Veiga, L.F., 2007. Os partidos brasileiros na perspectiva dos electores: mudanças e continuidades na identificação partidária e na avaliação das principias legendas após 2002. Opinião Pública, 13(2), pp.340-365. DOI: 10.1590/s0104-62762007000200005

Vommaro, G. 2006. Cuando el pasado es superado por el presente. Las lecciones presidenciales en 1983 y la construcción de un nuevo tiempo político en la Argentina. In A. Pucciarelli, ed. Los años de Alfonsín ¿El poder de la democracia o la democracia del poder? Buenos Aires: Siglo XXI.

Wattenberg, M.P., 1987. Do Voters Really Care about Political Parties Anymore? A Response to Craig. Political Behavior, 9(2), pp.114-125. DOI: 10.1007/bf00987301

\section{Otras fuentes}

Kolina Capital, 2017. ¿QUE ES KOLINA? Corriente de Liberación Nacional. Disponible en: http://kolinacapital.org/que-es-kolina/. Aceso en: 29 maio 2017.

LTIO Universidad, 2014. Rossi, Filmus y Taiana lanzaron la Corriente Nacional de la Militancia en Mar del Plata. Disponible en: http://www.lt10.com.ar/noticia/108125-Rossi-Filmus-y-Taiana-lanzaron-la-Corriente-Nacional-de-la-Militanciaen-Mar-del-Plata. Aceso en: 29 maio 2017. 
Missing the Party: Nostalgic References in Government-Supporting Activists in Argentina and Brazil (2003-2015)

\section{Abstract}

The paper examines and compares the presence of nostalgic references between militants of government-supporting organizations in Brazil and Argentina since the inauguration of Lula and Kirchner. As part of a wider research on grassroots activism within governments' political bases in both countries, the phenomenon of nostalgia observed in this study is interpreted as one of the two faces of the impact that political scenes of intense fluctuation in identities and volatility in electoral behavior have had over active militant groups: on one hand, an adaptation to those conditions of political life - through the transformation of the militant bonds and of the organizational formats of activism - and, on the other, a parallel phenomenon, which this paper specifically addresses of nostalgic appeals, referred to a past of rooted political identities and parties (or the interviewees' own party) with an intense everyday life and a strong bond with voters. The paper adopts a qualitative methodological perspective, taking into consideration the actors' own interpretations and conceptions and analyzing semi-structured interviews conducted in four districts: the cities of São Paulo and Rio de Janeiro, in Brazil, and the city of Buenos Aires and some of its suburban areas, with special focus in La Matanza, in Argentina (56 with government-supporting militants since 2013, and other of 74 interviews conducted for a previous research between 2005 and 2010 in the same locations). Through the association or clustering of different categories created during coding, we have identified two dimensions of nostalgia: first, references to a typical "past militant"; and, second, references to the context or exterior conditions in which political militants campaigned or acted. Findings from that qualitative analysis show an effective weight of those nostalgic references. It should be noted, however, that their presence is not homogeneous in both cases, or between the different organizations - it predominates among PT activists in Brazil and within the Peronist Party's (PJ) territorial networks in Argentina, but it fades when it comes to the new organizations that proliferated from outside the PJ in the past decade - or even between different generations of activists. Moreover, although the two dimensions of nostalgia mentioned before are frequent in the Brazilian actors' accounts, it is only the second dimension that prevails among the Argentine interviewees. The paper seeks to contribute to the academic debate on activism and political commitment today. Also, even in agreement with literature that suggests the weakening of structural and psychological links between parties and citizens, we argue the relevance of studying political militancy, which paradoxically has survived in those contexts of fluctuation.

KEYWORDS: activism; Argentina; Brazil; Workers' Party; Kirchner.

This is an Open Access article distributed under the terms of the Creative Commons Attribution Non-Commercial License which permits unrestricted non-commercial use, distribution, and reproduction in any medium provided the original work is properly cited. 